OPEN ACCESS

Edited by:

David Charles Gershlick

University of Cambridge,

United Kingdom

Reviewed by:

Katy Janvier

Université Paris Descartes, France

Elodie Mailler

National Institutes of Health (NIH),

United States

*Correspondence:

Luis L. P. daSilva

Ildasilva@fmrp.usp.br

tThese authors have contributed

equally to this work

Specialty section:

This article was submitted to

Membrane Traffic

a section of the journa

Frontiers in Cell and Developmental

Biology

Received: 28 October 2020

Accepted: 07 June 2021

Published: 08 July 2021

Citation:

Tavares $L A$, Januário $Y C$ and daSilva LLP (2021) HIV-1 Hijacking of Host ATPases and GTPases That

Control Protein Trafficking. Front. Cell Dev. Biol. 9:622610.

doi: 10.3389/fcell.2021.622610

\section{HIV-1 Hijacking of Host ATPases and GTPases That Control Protein Trafficking}

\author{
Lucas A. Tavarest, Yunan C. Januário ${ }^{\dagger}$ and Luis L. P. daSilva*
}

Department of Cell and Molecular Biology, Center for Virology Research, Ribeirão Preto Medical School, University of São

Paulo, Ribeirão Preto, Brazil

The human immunodeficiency virus (HIV-1) modifies the host cell environment to ensure efficient and sustained viral replication. Key to these processes is the capacity of the virus to hijack ATPases, GTPases and the associated proteins that control intracellular protein trafficking. The functions of these energy-harnessing enzymes can be seized by HIV-1 to allow the intracellular transport of viral components within the host cell or to change the subcellular distribution of antiviral factors, leading to immune evasion. Here, we summarize how energy-related proteins deviate from their normal functions in host protein trafficking to aid the virus in different phases of its replicative cycle. Recent discoveries regarding the interplay among HIV-1 and host ATPases and GTPases may shed light on potential targets for pharmacological intervention.

\section{Keywords: HIV-1, GTPases, ATPases, HIV-1 accessory proteins, HIV-1 pathogenesis, HIV-1 trafficking}

Abbreviations: HIV, human immunodeficiency virus; SIV, simian immunodeficiency virus; FIV, feline immunodeficiency virus; CCR5, C-C chemokine receptor type 5; CXCR4, C-X-C chemokine receptor type 4; AIDS, acquired immunodeficiency syndrome; HAART, highly active antiretroviral therapy; PIC, pre-integration complex; PM, plasma membrane; GDP, guanosine diphosphate; GTP, guanosine triphosfate; ATP, adenosine triphosphate; GAPs, GTPase-activating proteins; GEFs, guanine nucleotide exchange factors; ABC, ATP-binding cassette; Env, HIV envelope glycoprotein (precursor gp160, surface gp120, and transmembrane/cytosolic gp41); Gp41C, cytosolic tail of gp41; Nef, negative factor; Gag, groupspecific antigen; NC, nucleocapsid domain of Gag; MA, matrix domain of Gag; Pol, polymerase; Tat, trans-activator of transcription; Vpu, viral Protein U; Vif, viral infectivity factor; Vpr, viral protein R; Rev, regulator of virion expression; RREs, rev response elements; CME, clathrin-mediated endocytosis; Ran, Ras-related nuclear; TRN-SR2/TNPO3, transportinSR2; VLPs, virus-like particles; ARFs, ADP-ribosylation factors; GGA, golgi-localized, $\gamma$-ear containing, ARF-binding; AP, adaptor protein complex; RNAi, RNA interference; Rab, Ras-related in brain; BST2/Tetherin, bone marrow stromal cell antigen 2; DCs, dendritic cells; VSs, virological synapses; TGN, trans-Golgi network; ER, endoplasmic reticulum; MPRs, mannose 6-phosphate receptors; TIP47, tail-interacting protein of $47 \mathrm{kDa}$; ABCE1, ATP-binding cassette sub-family E member 1; TULA, T-cell ubiquitin ligand; FIP1C, Rab11-family interacting protein 1C; PI(4)P, phosphatidylinositol 4-phosphate; PI(4,5)P2, phosphatidylinositol (4,5)-bisphosphate; $\mathrm{PI}(3,4,5) \mathrm{P} 3$, phosphatidylinositol $(3,4,5)$-triphosphate; PI4KII $\alpha$, phosphatidylinositol 4-kinase type $2 \alpha$; Cdc42, cell division control protein 42 homolog; Rac1, Ras-related C3 botulinum toxin substrate 1; RhoA, Ras homolog family member A; DC-SIGN, dendritic cell-specific ICAM-3-grabbing nonintegrin; LARG, leukemia-associated Rho guanine nucleotide exchange factor (Rho GEF); Tiam1, T-lymphoma invasion and metastasis-inducing protein 1 (Rac GEF); ESCRT, endosomal sorting complex required for transport; HRS, hepatocyte growth factor-regulated tyrosine kinase substrate; VPS4, vacuolar protein sorting 4; ILVs, intraluminal vesicles; MVBs, multivesicular bodies; TSG101, tumor susceptibility gene 101; ALIX/AIP1/PDCD6IP, programmed cell death 6-interacting protein; CHMP, charged multivesicular body protein; ABCA1, phospholipid-transporting ATPase ABCA1; HDL, high-density lipoprotein; apoA-I, apolipoproteinA-1; ERAD, endoplasmic-reticulum-associated protein degradation; CCV, clathrin-coated vesicle; MHC-I, major histocompatibility complex I; PI3K, class I phosphatidylinositol 3-kinase; ARNO, ARF nucleotide-binding site opener. 


\section{INTRODUCTION}

The human immunodeficiency virus type 1 (HIV-1) is the etiologic agent of acquired immunodeficiency syndrome (AIDS) and the cause of one of the longest and most devastating viral pandemics in human history. Although highly active antiretroviral therapy (HAART) inhibits the spread of HIV-1, the currently available treatments do not eradicate the virus from infected individuals, and viral mutations may confer resistance to the available drugs. Therefore, research into additional therapeutic strategies against HIV-1 is of high importance. In almost 40 years of intensive study, much has been learned about how HIV-1 manipulates the molecular machinery of the host cell to its own benefit. HIV-1 hijacks many host proteins to ensure an efficient replication cycle and to evade the immune response, leading to pathogenesis.

The HIV-1 replicative cycle in a host cell can be divided into early and late phases. The early phase (Figure 1) extends from virus entry to the integration of the provirus into the host cell genome and includes events such as the uncoating of the viral capsid, the reverse transcription of viral RNA to cDNA, the formation of the preintegration complex (PIC) and the nuclear import of the PIC. Although the order of these events is under debate (previously reviewed in Toccafondi et al., 2021). The late phase (Figure 2) starts with the transcription of the viral RNAs and comprises their subsequent nuclear export to the cytoplasm, the translation of the viral proteins, the trafficking of structural proteins to virus assembly sites, and the assembly, budding and maturation of the viral particle (previously reviewed in Freed, 2015).

The efficient transport of virus-derived proteins and nucleic acids to and from specific membrane-bound compartments within the host cell is critical in several steps of the HIV1 replicative cycle. These translocation processes require specific transport and membrane remodeling machinery and a considerable amount of chemical energy provided by the host cell through ATP and GTP hydrolysis. Therefore, it is not surprising that HIV-1 co-opts several ATPases, GTPases and their regulators and effectors during infection and that these proteins are essential to virus replication and pathogenesis. Especially relevant among the GTPases are the small GTPases of the Ras superfamily, which are known to control critical processes implicated in intracellular trafficking. These include actin network dynamics, membrane specification, transport vesicle formation, translocation across the cytosol, and tethering to acceptor membranes. These monomeric proteins are found in GDP- or GTP-bound forms switching between inactive and active states in a cycle controlled by GAPs (GTPase-activating proteins) and GEFs (nucleotide exchange factors), respectively (previously reviewed in Itzen and Goody, 2011). When in their GTP-bound active state, these GTPases are membrane-associated and may interact with specific effector molecules.

This review presents examples and discusses data regarding the interplay between $\mathrm{HIV}-1$ and host ATPases and GTPases (Table 1) involved in the intracellular trafficking of macromolecules and membrane modification. We will also discuss cases in which the subcellular localization of transmembrane ATPases themselves is altered by HIV-1 to aid virus replication and spread. Host restriction factors with ATPase and GTPase activity acting against HIV will not be covered here, and we refer to recent reviews (Ghimire et al., 2018; Staeheli and Haller, 2018).

\section{HIV-1 CELL ENTRY}

HIV-1 enters cells mainly by fusing its envelope membrane to the plasma membrane (PM) of target cells (Figure 1). This process requires physical interactions between the gp120 subunit of the virus envelope (Env) protein and specific host proteins at the cell surface that function as the main receptor (CD4) (Maddon et al., 1986; Mcdougal et al., 1986) and as coreceptors (either CXCR4 or CCR5) (Alkhatib et al., 1996; Dragic et al., 1996; Feng et al., 1996) for the virus. These interactions expose a fusion domain in the gp41 subunit of Env, leading to membrane fusion and the delivery of the capsid containing the viral genome into the cytoplasm (Wilen et al., 2012).

There is also evidence, obtained mainly from non-canonical HIV-1 target cells, indicating that the virus may enter cells via endocytosis (Fackler and Peterlin, 2000; Fredericksen et al., 2002; Daecke et al., 2005). Consistent with this model, the impairment of endosome acidification by drug treatments was shown to compromise the infection of polarized trophoblasts with HIV, suggesting that incoming viruses are delivered to endosomes, where the acidic $\mathrm{pH}$ would facilitate membrane fusion (Vidricaire and Tremblay, 2005). In fact, the expression of small GTPases Rab5 or Rab7 mutants, known to impair endosome maturation, also inhibited HIV-1 infection in those cells (Vidricaire and Tremblay, 2005). Recently, Marin et al. (2019) found that the knockdown of Rab5, Rab11A or the Rab effector protein RABEP1 decrease HIV-1 fusion with endosomes in CD4+ T cells, highlighting the importance of the endocytic machinery in the HIV-1 entry process.

Regardless of the exact pathway, evidence from independent studies indicates that the GTPase Dynamin participates in the HIV-1 entry process (Daecke et al., 2005; Miyauchi et al., 2009; de la Vega et al., 2011; Jones et al., 2017). Dynamin is a GTPase best known for catalyzing membrane fission during clathrinmediated endocytosis (CME). Based on this well-characterized role, it was originally proposed that Dynamin is involved in HIV-1 entry by endocytosis, possibly via CME (Daecke et al., 2005; Miyauchi et al., 2009). The authors of this study showed that pharmacological inhibition of Dynamin or overexpression of a Dynamin dominant-negative (K44) mutant impaired HIV-1 infection (Miyauchi et al., 2009). However, the exact molecular connection between HIV entry and Dynamin was not elucidated.

A study by de la Vega and collaborators provided a hint on the mechanism by which Dynamin assists on HIV entry. They showed that Dynamin activity, which was inhibited with the drug dynasore, is required for the efficient fusion of the virus with target cell membranes and the release of the viral content into the cytosol (de la Vega et al., 2011). The authors proposed that in addition to playing a role in HIV-1 endocytosis, Dynamin may also facilitate virus fusion with the endosome membrane. Importantly, under dynasore treatment virus fusion with the PM was also impaired (de la Vega et al., 2011), most likely also 


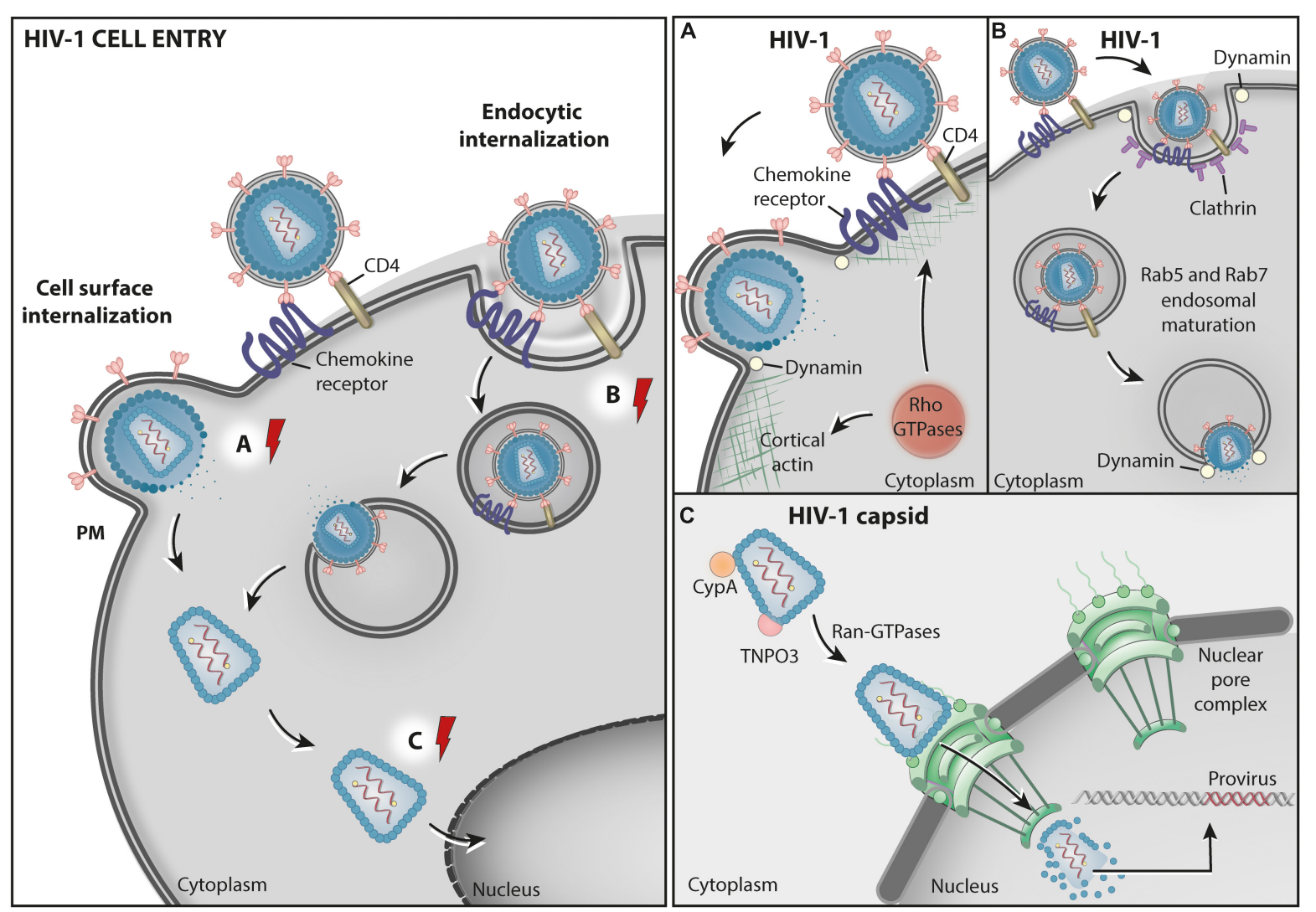

FIGURE 1 | HIV1 cell entry. Schematic representation of two proposed pathways for HIV-1 entry into cells. The cell surface internalization pathway involves the fusion between the viral envelope and the cell PM and is believed to be the main route for HIV entry into permissive CD4 expressing cells (A) - Rho GTPases: RhoA, Rac1, and Cdc42 participate in HIV-1 entry by promoting fusion complex stabilization, and fusion pore formation and expansion at the host cell surface through actin cytoskeleton remodeling. The HIV-1 entry pore is also stabilized by Dynamin GTPase activity, facilitating the release of the capsid containing the virus genome into the cytosol. In an alternative, poorly characterized, endocytic internalization entry pathway, HIV-1 particles are endocytosed via clathrin-coated vesicles (CCVs) and delivered to endosomes. (B) Dynamin GTPase activity is involved in both the formation of CCVs and the fusion between the virus and the endosome membrane. This pathway also involves Rab5 and Rab7 acting in endosomal maturation. (C) The viral capsid in the cytosol is transported to the nuclear pore by CypA, TNPO3, and the nuclear transporter GTPase Ran-GDP while the RNA is reverse transcribed into cDNA. At the nucleoplasm, the HIV-1 provirus is integrated into the host chromatin. The red electric ray symbols represent critical steps in the transport of viral factors that require energy.

contributing to inhibit viral entry in the experimental setup. Indeed, new data show that Dynamin participates in HIV-1 entry via a CME-independent mechanism (Aggarwal et al., 2017; Jones et al., 2017). In this process, Dynamin molecules associate to form tetramers that stabilize the HIV entry pore, facilitating the release of viral nucleocapsids into the cytosol through the actin cortex at the cell surface (Jones et al., 2017). The authors proposed that Dynamin may indirectly control this process by recruiting effector proteins. In support of this model, a previous report from Taylor et al. (2012) revealed that Dynamin proteins work cooperatively with actin and $\mathrm{N}$-terminal containing BAR (BIN/Amphiphysin/RVS) domain proteins at sites of membrane remodeling at the cell surface. The roles of actin cytoskeleton dynamics in HIV entry will be discussed later in this review (see section "Rho GTPases").

Finally, the fluidity of the PM, regulated by the presence of the lipid phosphatidylinositol $(4,5)$-bisphosphate [PI(4,5)P2], was shown to be crucial for HIV-1 entry in lymphocytes (Barrero-Villar et al., 2008). The small GTPase ADP ribosylation factor 6 (ARF-6) plays a significant role in this process by regulating the $\mathrm{PI}(4,5) \mathrm{P} 2$ enrichment at the inner leaflet of the PM. García-Expósito et al. (2011) showed that expression of ARF-6 mutants defective on GTP/GDP cycle caused the accumulation of $\mathrm{PI}(4,5) \mathrm{P} 2$-associated structures at the cell surface impeding CD4-dependent HIV-1 entry and infection, but without affecting CD4-viral attachment (García-Expósito et al., 2011). These results indicate that efficient early HIV-1 infection of permissive cells requires ARF6-mediated PM dynamics, possibly affecting pore formation.

\section{HIV-1 TRANSPORT TO THE NUCLEUS AND TRANSLOCATION TO THE NUCLEOPLASM}

The fusion of the HIV-1 envelope with the target cell membrane results in the delivery of the viral capsid containing the viral 


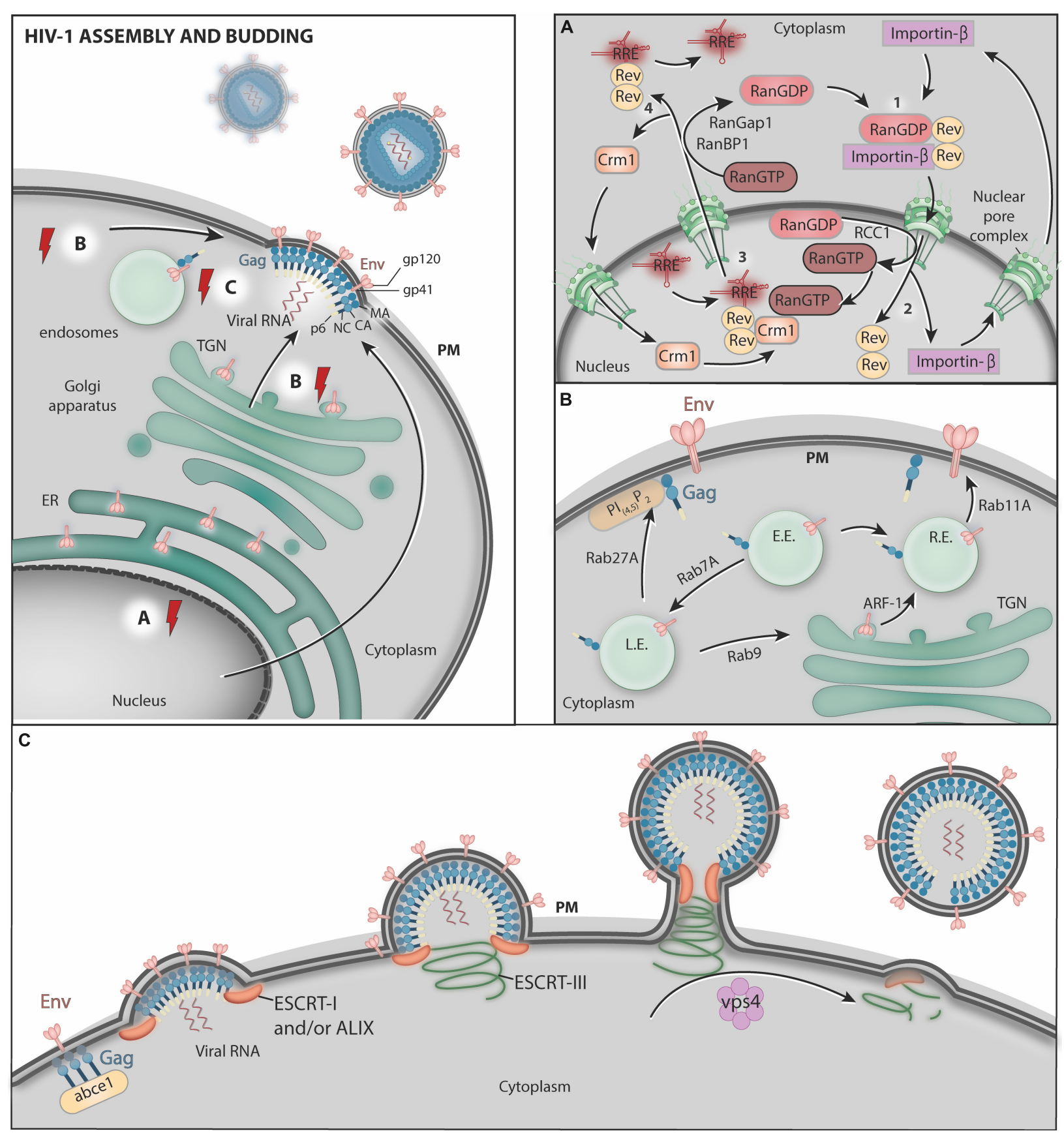

FIGURE 2 | HIV-1 assembly and budding. (A) The host transcriptional machinery transcribes the viral genes. After synthesis in the cytoplasm, Rev associates with RanGDP and Importin- $\beta$, forming the complex Rev-Importin- $\beta$-RanGDP which is imported into nucleus through nuclear pores (step 1). In the nucleus, the conversion of RanGDP to RanGTP mediated by RRC1 disassemble Rev from Importin- $\beta$, allowing Importin- $\beta$ to be exported back to the cytoplasm (step 2). Rev then binds RRE (present in viral RNA molecules), RanGTP, and Crm1 and the Crm1-RanGTP-Rev-RRE complex exits the nucleus through the nuclear pores (step 3). After the translocation to the cytoplasm, RanGTP is converted to RanGDP by RanGAP1 and RanBP1, allowing the disassembly of the complex, and Crm1 is imported again to the nucleus while transported viral RNAs are free to be translated (step 4). (B) Env is synthesized in association with the ER membrane and transported to the Golgi complex. After reaching the Golgi, Env is transported to the PM, where new HIV-1 particles are formed. This trafficking occurs via transport vesicles that require ARF-1 GTPase. Rab GTPases control several steps of HIV-1 structural protein trafficking in endosomes. Rab7A is required for mature Env incorporation into nascent virus particles. Rab9 was proposed to Env and Gag from the endolysosomal pathway back to the Golgi complex. This process reroutes HIV-1 proteins to virus assembly sites at the PM. Rab11 controls the pathway that recycles Env from the cell surface to endosomes and back to the PM. Rab27a activity helps to target Gag to virus assembly sites at the PM. Moreover, Rab8 and Rab7L1 (Rab29) activity are exploited by HIV-1 during trans-infection from dendritic cells (DCs) to target T cells via virological synapses (not shown). L.E., late endosomes; E.E., early endosomes; R.E., recycling endosomes. (C) Finally, ABCE1 facilitates Gag organization at the cell surface, where the ESCRT machinery and the AAA-ATPase VPS4 facilitate virus particle release. The red electric ray symbols represent critical steps in the transport of viral factors that require energy. 
TABLE 1 | ATPases and GTPases co-opted by HIV-1 during its replication cycle are presented in the order that they appear in the text.

\begin{tabular}{|c|c|c|}
\hline ATPase/GTPase & Process in the HIV-1 replicative cycle & References \\
\hline Dynamin & $\begin{array}{l}\text { - Viral membrane fusion with the host cell. } \\
\text { - Stabilization of the HIV-1 entry pore. } \\
\text { - Work together with Actin and Bar domain proteins to facilitate } \\
\text { the release of viral nucleocapsid into the cytosol. }\end{array}$ & $\begin{array}{l}\text { Miyauchi et al., 2009; de la Vega et al., 2011; Taylor et al., 2012; Aggarwal } \\
\text { et al., 2017; Jones et al., } 2017\end{array}$ \\
\hline Rab5 and Rab7 & - Involved in endocytic entry of HIV-1 & Vidricaire and Tremblay, 2005; Marin et al., 2019 \\
\hline Ran & $\begin{array}{l}\text { - HIV PIC nuclear import. } \\
\text { - Interacts with TRN-SR2 to release HIV PIC in the nucleoplasm. } \\
\text { - Nuclear egress of Crm1-Rev-RRE-cargo complex. } \\
\text { - Ran GDP, together with Importin- } \beta \text {, promotes Rev nuclear } \\
\text { import. }\end{array}$ & $\begin{array}{l}\text { Malim et al., 1989a; Fornerod et al., 1997; Henderson and Percipalle, 1997; } \\
\text { Neville et al., 1997; Askjaer et al., 1998; Christ et al., 2008; König et al., } \\
\text { 2008; Dong et al., 2009; Monecke et al., 2009; Güttler et al., 2010; } \\
\text { Krishnan et al., 2010; De laco and Luban, 2011; Zhou et al., 2011; Larue } \\
\text { et al., 2012; Valle-Casuso et al., 2012; Taltynov et al., 2013; Behrens et al., } \\
2017\end{array}$ \\
\hline ABCE1 & - HIV-1 assembly. & $\begin{array}{l}\text { Lingappa et al., 1997, 2006; Zimmerman et al., 2002; Dooher and } \\
\text { Lingappa, 2004; Dooher et al., 2007; Klein et al., 2011; Reed et al., } 2018\end{array}$ \\
\hline ARF-1 & $\begin{array}{l}\text { - Viral particle production. } \\
\text { - Trans-infection at virological synapse. }\end{array}$ & Joshi et al., 2008, 2009b; Bayliss et al., 2020 \\
\hline ARF-3 & - Viral particle production. & Joshi et al., 2008 \\
\hline $\mathrm{ARF}-5$ & - Viral particle production. & Joshi et al., 2008 \\
\hline ARF-6 & $\begin{array}{l}\text { - Regulates CD4-dependent HIV-1 entry and infection by } \\
\text { controlling PI(4,5)P2 dynamics at PM. }\end{array}$ & García-Expósito et al., 2011 \\
\hline Rab7A & $\begin{array}{l}\text { - Env processing. } \\
\text { - Env incorporation into virions. } \\
\text { - Release of the viral particle. }\end{array}$ & Caillet et al., 2011 \\
\hline Rab7L1 (Rab29) & - Trans-infection at virological synapse. & Bayliss et al., 2020 \\
\hline Rab8A & - Trans-infection at virological synapse. & Bayliss et al., 2020 \\
\hline Rab9 & $\begin{array}{l}\text { - Viral particle production. } \\
\text { - Gag transport to HIV-1 assembly site. } \\
\text { - Together with TIP47, help the retrograde transport of Env from } \\
\text { endosome to TGN. }\end{array}$ & Blot et al., 2003; Murray et al., 2005 \\
\hline Rab11A & $\begin{array}{l}\text { - Control the levels of cellular and viral particle-associated Env. } \\
\text { - FIP1C (Rab11 effector) reroutes Env to recycling endosomes. }\end{array}$ & Qi et al., 2013; Kirschman et al., 2018 \\
\hline Rab27A & $\begin{array}{l}\text { - Participates in Gag, } \mathrm{PI} 4 \mathrm{KIl} \alpha \text { and } \mathrm{Pl}_{(4,5)} \mathrm{P}_{2} \text { levels at cell surface. } \\
\text { - HIV-1 assembly. } \\
\text { - Trans-infection at virological synapse. }\end{array}$ & Gerber et al., 2015 \\
\hline Rac1 & $\begin{array}{l}\text { - Promote pore formation and expansion during HIV-1 entry } \\
\text { - control Gag levels at the cell surface and VLP release. } \\
\text { - Gag expression activates Rac1 and increases F-actin content. }\end{array}$ & $\begin{array}{l}\text { Pontow et al., 2004, 2007; Harmon et al., 2010; Vorster et al., 2011; } \\
\text { Thomas et al., } 2015\end{array}$ \\
\hline RhoA & $\begin{array}{l}\text { - HIV-1 entry via stabilization of the fusion complex. } \\
\text { - gp41 binds p115-RhoGEF which play a role in viral replication. } \\
\text { - Control monocyte migration and adhesion, which may affect } \\
\text { HIV-1 dissemination. } \\
\text { - Activation of a RhoA-ROCK-LIMK-Cofilin signaling cascade } \\
\text { mediated by Filamin-A facilitates HIV-1 entry }\end{array}$ & $\begin{array}{l}\text { Zhang et al., 1999; Wang L. et al., 2000; Hodges et al., 2007; } \\
\text { Jiménez-Baranda et al., 2007; Lucera et al., } 2017\end{array}$ \\
\hline Cdc42 & $\begin{array}{l}\text { - Promotes plasma membrane expansions that facilitate viral } \\
\text { transfer from DCs to T cells } \\
\text { - Promotes HIV-1 T cell infection. }\end{array}$ & Nikolic et al., 2011; Shrivastava et al., 2015; Lucera et al., 2017 \\
\hline VPS4 & - ESCRT-dependent HIV-1 assembly and budding. & $\begin{array}{l}\text { Baumgärtel et al., 2011; Jouvenet et al., 2011; Bleck et al., 2014; Van } \\
\text { Engelenburg et al., 2014; Johnson et al., } 2018\end{array}$ \\
\hline
\end{tabular}

genomic RNA (gRNA) into the cytoplasm (Figure 1). The HIV1 capsid core comprises a conical structure made of capsid (CA) protein, which contains the gRNA and copies of the viral reverse transcriptase and integrase enzymes. In addition to protecting the viral genome from host restriction factors and innate immunity recognition, the capsid provides an optimized environment for reverse transcription, leading to the synthesis of viral DNA that is, ultimately, integrated into the host cell chromatin to form a provirus (Figure 1).

Viral capsid uncoating/disassembly is required for integration and productive infection. However, the timing and location of capsid disassembly is still a matter of debate, with models proposing that it occurs either at the cytoplasm, at the nuclear pore, or within the nucleus (previously reviewed in Toccafondi et al., 2021). Several recent studies favor a model in which capsid disassembly occurs after complete nuclear translocation by providing evidence that reverse transcription finalizes within the nucleus and that the capsids enter the nucleus and remain intact (or nearly intact) until they uncoat near the integration sites, just minutes before integration (Burdick et al., 2020; Dharan et al., 2020; Selyutina et al., 2020; Li et al., 2021). The recent direct visualization of apparently intact, cone-shaped HIV-1 capsids 
being imported through nuclear pores in infected T cells provides definite proof that capsid uncoating may occur after nuclear transport is complete (Zila et al., 2021).

The nuclear pore complexes and the soluble transport receptors of the karyopherin family of proteins mediate the transport of macromolecules across the nuclear envelope. This process requires an input of energy derived from GTP hydrolysis by Ras-related nuclear (Ran) small GTPases, which provide selectivity and directionality to the nuclear translocation process. Interaction between GTP-bound Ran (Ran-GTP) and nuclear transport receptors directs the binding and release of cargo, and the enrichment of Ran-GDP in the cytoplasm and RanGTP in the nucleoplasm forms a gradient that controls the bidirectional flow of molecules in and out of the nucleus (Koyama and Matsuura, 2010).

Several components of the nuclear transport machinery are required for HIV infection, including the $\beta$-karyopherin Transportin-SR2 (TRN-SR2, also known as TNPO3) (Brass et al., 2008; Christ et al., 2008; König et al., 2008). Consistent with a model in which HIV-1 hijacks the Ran-GTPase system to invade the nucleus, Taltynov et al. (2013) observed that TNPO3 associates with Ran-GTP, which may facilitate the release of viral material in the nucleoplasm. TNPO3 requirement during HIV-1 and other lentivirus infection was correlated to capsid binding and proposed to occur after nuclear entry (Krishnan et al., 2010; De Iaco and Luban, 2011; Valle-Casuso et al., 2012). Interestingly, recombinant TNPO3 stimulates the uncoating of $\mathrm{HIV}-1$ cores in vitro, a property that is inhibited by the CA-binding host protein cyclophilin A (CypA) (Shah et al., 2013). This relationship between TNPO3 and CypA suggests that these proteins coordinate proper disassembly of the viral capsid in target cells, with TNPO3 favoring capsid disassembly within the nucleus.

Although TNPO3 was shown initially to bind integrase (Christ et al., 2008), the role of this interaction in HIV-1 infection is presently not clear (Cribier et al., 2011) and, in light of new data discussed above, may occur within the nucleus. Nevertheless, a library with more than 25,000 small molecules was recently screened for inhibitors of the HIV-1 integraseTNPO3 interaction, and new compounds that significantly reduce HIV-1 integration were identified (Demeulemeester et al., 2018). These compounds may represent potential future drugs to treat HIV infection. Despite these advances, much remains to be learned about the process by which HIV-1 material is imported into the nucleus, as other host factors are likely to be required for this process. The emerging candidates include importin $\alpha$, importin $\beta$, and importin 7 , but divergent data indicate a complex process, and other proteins may also be involved (previously reviewed in Matreyek and Engelman, 2013).

\section{NUCLEAR EXIT OF HIV PRODUCTS}

The late phase of the HIV-1 replication cycle starts with provirus gene expression (Figure 2). The transcription of the HIV1 genome is mediated by host cell RNA polymerase II and initiates from the U3 promoter region within the proviral $5^{\prime} \mathrm{LTR}$.
To achieve maximum production, this process is enhanced by the viral regulatory protein Tat (transactivator of transcription) (Siekevitz et al., 1987). HIV-1 RNA synthesis and downstream processing result in the production of a variety of RNA species, including completely spliced mRNA molecules [encoding the Tat, regulator of expression of virion proteins (Rev), and negative factor (Nef) proteins], partially spliced mRNAs (encoding the structural proteins Gag, Pol and Env), and unspliced gRNA (previously reviewed in Cullen, 2003), which need to reach the cytosol for protein synthesis and/or virion assembly.

HIV-1 RNA export from the nucleus is mainly mediated by the regulatory protein Rev, which facilitates the nuclear export and cytoplasmic build-up of singly spliced and unspliced viral RNA molecules (Malim et al., 1989b) through an energy-consuming process. Rev binds and oligomerizes to Rev response elements (RREs) present in viral RNA molecules, allowing the formation of ribonucleoproteins that are competent for nuclear export. This process evades the host cell quality control mechanisms that prevent the nuclear export of incompletely spliced RNA molecules (Malim et al., 1989a). The Rev-RRE ribonucleoprotein complex interacts with host export factor Crm1, an karyopherin family member, also known as exportin 1 (Xpo1) (Fornerod et al., 1997; Güttler et al., 2010).

The nuclear egress of the Crm1-Rev-RRE-cargo complex through nuclear pores is an energy-dependent process. This event is controlled by Ran GTPase, which enables the formation of the Crm1-RanGTP-Rev-RRE-cargo complex. In fact, Ran in its active (GTP-bound) form mediates the interaction between Crm1 and Rev through a surface-exposed hydrophobic pocket on Crm1 (Dong et al., 2009; Monecke et al., 2009; Güttler et al., 2010). Recently, Behrens et al. (2017) have shown that Rev tolerates several nuclear export signals, even those that bind Crm1 in a Ran-GTP-independent manner. Additionally, interactions between Rev proteins may mask their nuclear export signals and favor the nuclear accumulation of Rev (Behrens et al., 2017).

Once in the cytoplasm, the Crm1-RanGTP-Rev-RRE-cargo complex is dissociated as a consequence of GTP hydrolysis induced by RanGAP1 and RanBP1, which releases Cmr1 and RanGDP from the Rev-RRE-cargo complex (Neville et al., 1997; Askjaer et al., 1998). Thereafter, the RRE disassociates from Rev and the RRE-RNA is translated, whereas Crm1 is reimported into the nucleus. In the cytoplasm, an importin- $\beta$ binds to the nuclear localization signal of Rev and, combined with RanGDP, promotes the nuclear import of Rev via the nuclear pores (previously reviewed in Meyer and Malim, 1994; Truant and Cullen, 1999; Suhasini and Reddy, 2009). In the nucleus, the disassembly of the Rev-RanGDP-Importin- $\beta$ complex is triggered by the conversion of RanGDP to RanGTP, resulting in the release of Rev to facilitate further viral RNA nuclear export (previously reviewed in Meyer and Malim, 1994; Henderson and Percipalle, 1997; Suhasini and Reddy, 2009).

\section{HIV-1 ASSEMBLY AND BUDDING}

The HIV-1 structural proteins Gag and Env are synthesized in the cytosol and in association with the endoplasmic reticulum 
(ER) membrane, respectively, and their correct targeting to viral assembly sites is crucial in HIV-1 replication (Figure 2). Although Gag protein is sufficient for the assembly and budding of viruslike particles (VLPs) (Gheysen et al., 1989) as well as for the recruitment and packaging of the viral genome into VLPs (Shields et al., 1978; Sakalian et al., 1994), the proper incorporation of Env glycoproteins into the nascent virion is essential to the production of infectious particles. Depending on the cell type, HIV-1 assembly has been proposed to take place at the inner leaflet of the PM (Ono et al., 2000; Ono and Freed, 2004), at the intraluminal vesicles (ILVs) of late endosomes/multivesicular bodies (MVBs) (Nydegger et al., 2003; Sherer et al., 2003; Joshi et al., 2009a) or at intracellular compartments connected to the cell surface by tubules (Bennett et al., 2009). However, how Env and Gag reach the sites of viral assembly in each case is not fully understood. Intense study on this subject has revealed a number of host ATPases and GTPases involved in HIV-1 particle morphogenesis and budding.

\section{Small GTPases Regulating the Intracellular Trafficking and Subcellular Distribution of HIV-1 Structural Proteins ARF GTPases}

The ADP-ribosylation factors (ARFs) form a protein family within the Ras superfamily of small GTPases (previously reviewed in D'Souza-Schorey and Chavrier, 2006) and play important roles in intracellular vesicle trafficking, actin remodeling and phospholipid metabolism (previously reviewed in Kahn et al., 2005; D'Souza-Schorey and Chavrier, 2006; Gillingham and Munro, 2007; Randazzo et al., 2007; Kahn, 2009). In the context of HIV-1 infection, cellular depletion of ARF-1, ARF-3 or ARF-5 levels by RNAi or the expression of dominant-active forms of these molecules was shown to impair HIV-1 particle production (Joshi et al., 2008).

ARF molecules may initiate the formation of transport vesicles by recruiting vesicle coat components to specific donor membranes. Among the vesicle coat proteins recruited by ARFs are the monomeric Golgi-localized, $\gamma$-ear containing, ARFbinding (GGA) adaptors (Boman et al., 2000; Dell'Angelica et al., 2000) and members of the adaptor protein (AP) complex family (Stamnes and Rothman, 1993; Traub et al., 1993). GGAs and APs are sorting adaptors involved in protein trafficking in the late secretory pathway and have been implicated in the intracellular transport of Gag and Env. Specifically, GGA1-3 (Joshi et al., 2008, 2009b), AP-1 (Camus et al., 2007), AP-2 (Batonick et al., 2005), AP-3 (Dong et al., 2005; Garcia et al., 2008; Alford et al., 2016), and AP-5 (Alford et al., 2016) have been described to play key roles in the correct targeting of Gag to viral assembly sites. GGA overexpression was shown to compromise viral particle production, and mutation of the ARF-binding sites in GGAs abrogated this phenotype (Joshi et al., 2008, 2009b). The authors of this study suggested that GGA overexpression hinders viral production by sequestering free ARF-1 molecules and thus impairing its activity.

The HIV-1 Env polyprotein precursor gp160 is processed in the Golgi complex to produce gp120 (surface glycoprotein) and gp41 (hydrophobic transmembrane glycoprotein), which are bound to each other in a non-covalent manner (McCune et al., 1988; Freed et al., 1989; Stein and Engleman, 1990; Hallenberger et al., 1992). Importantly, gp160 processing is essential for efficient HIV-1 membrane fusion and infectivity (McCune et al., 1988; Freed et al., 1989; Bosch and Pawlita, 1990; Guo et al., 1990; Dubay et al., 1995). From the Golgi, gp120-gp41 heterodimers are transported to the cell surface, possibly via endosomes, in an ARF-1/AP-1-dependent manner (Berlioz-Torrent et al., 1999; Wyss et al., 2001).

Recently, an RNAi-based screen of membrane trafficking regulators showed that ARF-1 depletion in dendritic cells (DCs) reduced the transfer of viral particles to $\mathrm{T}$ cells by rerouting Gag molecules away from the sites of virological synapsis, leading to virus particles accumulation in small vesicle structures at the donor cell periphery (Bayliss et al., 2020). However, this inhibitory effect in virus transfer may not be merely due to altered Gag trafficking, because ARF-1 depletion also affected the delivery of virological synapse (VSs) structural proteins to the PM, such as the tetraspanin CD81 (Bayliss et al., 2020). Therefore, it is not currently possible to conclude whether ARF-1 plays a direct role in Gag trafficking and HIV-1 cell-to-cell transfer.

\section{Rab GTPases}

The Rab (Ras-related in brain) proteins form another family of small GTPases involved in the trafficking of HIV-1 Gag and Env. In general, Rabs provide identity and function to the membranes of secretory pathway compartments with multiple functions in vesicle transport (previously reviewed in Lamber et al., 2019; Homma et al., 2021). The roles of Rab proteins in viral replication have been recently reviewed (Spearman, 2018). Regarding HIV, a study by Caillet et al. (2011) implicated the activity of several Rab proteins (Rab4A, Rab6A, Rab7A, Rab8A, Rab9A, and Rab11A) in viral replication. Among these Rabs, the function of Rab7A (an endosome-associated Rab) was described as being the most important for efficient HIV-1 particle production (Caillet et al., 2011). The authors showed that the depletion of Rab7A impairs both Env processing and the incorporation of mature Env into viral particles, compromising viral infectivity. Moreover, Rab7A depletion hampers the release of HIV-1 progeny, which accumulates at the cell surface (Caillet et al., 2011). Interestingly, this phenotype was dependent on the expression of the host restriction factor BST2/Tetherin, which is normally antagonized by the HIV-1 accessory protein viral protein $\mathrm{U}$ (Vpu) (Neil et al., 2008); this process is discussed later in this review (see section "Vpu"). Furthermore, a recent study showed that trafficking pathways controlled by Rab8A and Rab7L1 (also known as Rab29) are exploited by HIV-1 during trans-infection from DCs to target T cells via VSs. The authors showed that the depletion of Rab8A and Rab29 in DCs leads to a reduction in HIV-1 localization at VSs and a consequent accumulation of Gag and CD81, a host tetraspanin that is normally recruited to VSs, in intracellular compartments (Bayliss et al., 2020).

Another Rab potentially involved in HIV-1 replication is Rab9 (Murray et al., 2005). Rab9 was originally linked to protein transport between endosomes and the TGN (Lombardi et al., 1993; Shapiro et al., 1993; Riederer et al., 1994) and more recently 
to lysosomes and lysosome-related organelles biogenesis and autophagy (Riederer et al., 1994; Ganley et al., 2004; Nishida et al., 2009; Kloer et al., 2010). Using gene-trap insertional mutagenesis and RNAi assays, it was found that interfering with Rab9 activity causes the rerouting of Gag to lysosomes and a decrease in HIV-1 particle production (Murray et al., 2005). Interestingly, TIP47 (also known as Perlipin-3), a Rab9 interacting protein originally implicated in protein trafficking (Díaz and Pfeffer, 1998; Hanna et al., 2002) and more recently in lipid droplet biogenesis (Wolins et al., 2001; Bulankina et al., 2009), was proposed to play a role in HIV-1 particle biogenesis (Blot et al., 2003; Lopez-Vergès et al., 2006). A study showed that TIP47/Perlipin-3 binds Env via a di-aromatic $\mathrm{Y}_{802} \mathrm{~W}_{803}$ motif in gp41 that is required for proper retrograde transport of Env from endosomes to the TGN and for Env incorporation into virions (Blot et al., 2003). TIP47 also interacts with Gag via the matrix (MA) domain, and a study show that Env incorporation was inhibited by TIP47 depletion or by the disruption of the Gag-TIP47 interaction (Lopez-Vergès et al., 2006). The authors proposed that TIP47 may function as a connector between Env and Gag, controlling proper Env incorporation during viral particle assembly. However, this notion was challenged by a more recent study (Checkley et al., 2013). Although TIP47 interaction with MA was confirmed, the authors of this other study did not observe changes in Env incorporation, virus release, infectivity, or replication upon TIP47 depletion in either HeLa cells or Jurkat $\mathrm{T}$ cell lines. Therefore, the mechanism by which Rab9 and TIP47 affect HIV-1 replication remains unclear.

Strong evidence for the ability of HIV-1 proteins to coopt Rabs and Rab effectors in recycling endosome-mediated pathways has also come to light. Rab11 is one of the main regulators of membrane recycling in the late secretory pathway (Ullrich et al., 1996; Casanova et al., 1999; Wang X. et al., 2000; Hales et al., 2001). Although Rab11A depletion does not alter Env incorporation into virions, the expression of a Rab11A active (GTP-bound) form decreases the levels of cellular and particle-associated Env (Qi et al., 2013). Consistent with this result, Env expression modifies the localization of the Rab11 effector FIP1C from recycling endosomes to the cell periphery, and FIP1C depletion reduces the levels of Env in cells and nascent viral particles, delaying HIV-1 replication (Qi et al., 2013). Furthermore, the expression of a C-terminal fragment of FIP1C (FIP1C $560-649)$ reroutes Env to recycling endosomes and diminishes the levels of Env on the cell surface and the incorporation of Env into virions (Kirschman et al., 2018). The function of Rab11/FIP1C may also involve Rab14 because the expression of a FIP1C mutant $\left(\mathrm{S}_{580} \mathrm{~N} / \mathrm{S}_{582} \mathrm{~L}\right)$ that does not bind Rab14 similarly depletes Env from the viral particles (Qi et al., 2013), a phenotype recapitulated by the expression of an inactive GDP-bound Rab14 (Rab14S ${ }_{25}$ N) (Qi et al., 2013).

Importantly, it is known that the lipid phosphatidylinositol $(4,5)$-bisphosphate $[\mathrm{PI}(4,5) \mathrm{P} 2]$ present in the inner leaflet of the PM plays an essential role in Gag localization at the PM (Ono et al., 2000; Ono and Freed, 2004). In a process called the "myristoyl switch," the binding of the negatively charged inositol headgroup of PI $(4,5) \mathrm{P} 2$ to the MA domain of Gag exposes the $\mathrm{N}$-terminal myristoyl group present in the MA domain, which mediates the anchorage and stabilization of Gag at the PM (Ono et al., 2000; Ono and Freed, 2004; Brügger et al., 2006; Saad et al., 2006; Shkriabai et al., 2006). Additionally, Gag traps PI(4,5)P2 and cholesterol, suppressing their mobility at the T cell PM and creating an efficient microdomain platform for virus assembly (Favard et al., 2019). Taking these findings into consideration, Gerber et al. (2015) carried out a study that revealed that Rab27A controlled PI(4,5)P2 levels at HIV-1 assembly sites by directing the enzyme PI4KII $\alpha$ (phosphatidylinositol 4-kinase type $2 \alpha$ ) from late endosomes to the PM, where PI4KII $\alpha$ produces phosphatidylinositol 4-phosphate [PI(4)P], a precursor of PI(4,5)P2 (Rameh et al., 1997; Doughman et al., 2003). Therefore, the depletion of Rab27A reduced the pools of PI4KII $\alpha$ and PI(4,5)P2 at the cell surface, reducing Gag association with the PM and HIV-1 assembly/production (Gerber et al., 2015). Although the trafficking and processing of Env were not affected in Rab27A-silenced cells, Rab27A ablation impaired HIV-1 cellto-cell spread either through free viral particles or by transinfection at the VSs (Gerber et al., 2015). Finally, expression of the Rab27A effector proteins Slac2b, Slp2a, and Slp3 was also shown to be required for Gag association with the PM and efficient HIV-1 particle production (Gerber et al., 2015). Altogether, these results demonstrate an important role for Rab27A and its effector proteins in HIV-1 production and spread through a PI4KII $\alpha$ trafficking mechanism.

\section{Rho GTPases}

The Rho GTPase family (including Cdc42, Rac1, and RhoA) regulates multiple cellular processes involving the activation of signaling pathways, such as cell adhesion, migration, survival, differentiation, and proliferation (Tybulewicz and Henderson, 2009). Given the intricate manipulation of host cell signaling by HIV-1, it is not surprising that several studies have reported that Rho GTPases are involved in various events in the HIV1 replication cycle. Rho GTPases are especially relevant in the host actin cytoskeleton subversion by HIV-1, a recently reviewed subject (Stella and Turville, 2018). There is strong evidence that incoming HIV-1 particles interfere with actin cytoskeleton dynamics at the target cell cortex by triggering the activation of signaling cascades mediated by distinct Rho GTPases (Figure 1).

Jiménez-Baranda et al. (2007) showed that the interaction of Env with CD4 and the chemokine coreceptors (CCR5 and CXCR4) promote F-actin stabilization via phosphorylation (and inactivation) of Cofilin, an F-actin depolymerizing factor (Jiménez-Baranda et al., 2007). The LIM domain kinase 1 (LIMK1), a protein that phosphorylates Cofilin is activated by RhoA or Rac1 effectors ROCK and PAK-1, respectively (Maekawa et al., 1999; Vadlamudi et al., 2002; Jiménez-Baranda et al., 2007). Interestingly, Filamin-A, an actin cross-linking protein that binds ROCK and PAK-1 (Ohta et al., 2006), also interacts with CD4, CCR5, and CXCR4 (Jiménez-Baranda et al., 2007), and this interaction was shown to be required for Env-mediated RhoA activation, Cofilin phosphorylation, and efficient HIV-1 infection. Since HIV-1 infection was impaired by a ROCK inhibitor, and not by disruption of Rac1 or PAK-1 activity, it was proposed that Filamin-A mediates 
activation of a RhoA-ROCK-LIMK-Cofilin signaling cascade that facilitates HIV-1 entry via stabilization of the fusion complex (Jiménez-Baranda et al., 2007).

In contrast, work from other groups support a crucial role for Racl activation in promoting HIV infectivity. Vorster et al. (2011) showed that HIV-1 infection, or gp120 treatment, activates Rac1 and induces PAK-mediated activation of LIMK1, leading to phosphorylation and inactivation of Cofilin in resting CD4 $\mathrm{T}$ cells (Vorster et al., 2011). In fact, the interaction of Env with CD4 and CCR5 or CXCR4 was shown to trigger a defined Gaq-mediated signaling cascade activating Rac1 to promote actin polymerization events at the cell cortex that facilitates fusion (Pontow et al., 2004; Harmon and Ratner, 2008). Further studies into this mechanism show that this Env-induced signaling cascade activates the tyrosine kinase Abl that stimulates the Rac GEF Tiam-1 to activate Racl. Subsequently, Abl and Rac1-GTP activate the Wave2 complex, which stimulates actin polymerization via the Arp2/3 complex (Harmon et al., 2010). Because pharmacological inhibition of $\mathrm{Abl}$ was shown to arrest Env-mediated membrane fusion at the hemifusion step, the authors of this study proposed that actin remodeling mediated by $\mathrm{Abl}$ and $\mathrm{Racl}$ promote pore formation and expansion during HIV-1 entry (Harmon et al., 2010).

Binding of Env to target cells was also shown to activate Cdc42 and contribute to viral spreading. Env-binding to the DCSIGN protein in the surface of DCs, triggers Cdc42 activation via a c-Src cascade leading to filopodia formation via the Arp2/3 complex and Diaphanous 2. These PM expansions in DC cells where shown to facilitate viral transfer to T cells (Nikolic et al., 2011; Shrivastava et al., 2015). Moreover, DC-SIGN stimulation by HIV-1 in monocyte-derived DCs results in a complex formation containing DC-SIGN, Rho and a Rho GEF called leukemia-associated Rho guanine nucleotide exchange factor (Rho GEF) (LARG) (Hodges et al., 2007). The Rho activation mediated by LARG via DC-SIGN is essential for optimal HIV-1 replication and VS formation (Hodges et al., 2007). The extensive manipulation of Rho GTPases pathways during HIV entry was nicely illustrated in a recent study by Lucera et al. (2017). Using a phosphoproteomics approach, the authors confirmed that HIV binding to CD4 and CCR5 activates Rac1 and Cdc42 leading to dramatic changes in the phosphorylation status of proteins associates to GTPase signaling (Lucera et al., 2017).

While the importance of Rho GTPases activity in HIV entry and spreading seems to be a consensus in the field, the relative importance of the family members (either Cdc42, Rac1, or RhoA) in the specific process has been a matter of controversy. This difficulty is partially due to the great degree of overlap and crosstalk among the Rho GTPases signaling pathways with shared regulators and downstream effectors. For instance, the LIMK-Cofilin pathway unites all three major Rho GTPases. The increasing availability of specific inhibitors targeting the GTPases themselves will help clarify the individual functions of Rho GTPases in HIV replication processes and provide valuable tools to fight infection.

Besides their role in virus entry, there is a well-documented interplay between Rho GTPases and the HIV-1 structural proteins during viral assembly/replication. It has been demonstrated that the cytosolic tail of HIV-1 gp41 (gp41C) binds the regulatory domain of p115 (Zhang et al., 1999), a RhoA GEF (Hart et al., 1996). This interaction is functionally relevant since the disruption of the p115-RhoGEF binding site in gp41 (Zhang et al., 1999) or the overexpression of a p115-RhoGEF activator (Wang L. et al., 2000) were shown to inhibit HIV-1 replication. Moreover, gp41C expression inhibited p115-RhoGEF-mediated actin stress fiber formation (Zhang et al., 1999), suggesting that HIV-1 regulates RhoA activity via its GEF. Because RhoA activity was shown to normally regulate the cell survival (Galandrini et al., 1997) and migration (Aepfelbacher et al., 1996) of HIV-1 target cells, the gp41C-p115RhoGEF interaction and RhoA activity are likely to affect HIV-1 dissemination and pathogenesis (Zhang et al., 1999; Wang L. et al., 2000).

Finally, the trafficking of Gag to HIV-1 assembly sites was shown to be dependent on Rac1, where the levels of Gag at the PM and the release of HIV-1 Gag VLPs were inhibited in Rac1-depleted $T$ cells (Thomas et al., 2015). In fact, the efficient production of HIV-1 Gag VLPs requires a functional Rac1Wave2-IRSp53-Arp2/3 pathway in T cells (Thomas et al., 2015). Although, the HIV-1 accessory protein Nef potently induces Rac1 activation (as discussed later in this review, see section "Nef") and may contribute to the role of Rac1 in virus release, Gag expression alone activates Rac1 and increases intracellular F-actin content (Thomas et al., 2015).

\section{ATPases Involved in HIV Budding The ATPAse ABCE1}

The membrane budding process driven by the HIV-1 Gag protein requires ATP, given that it is inefficient in ATP-depleted cells (Lingappa et al., 1997; Tritel and Resh, 2001). Since HIV1 Gag does not itself interact with ATP and it is unable to harness its stored chemical energy, researchers sought to identify a host protein that could serve as an adaptor in this process. Using coimmunoprecipitation assays, Lingappa's lab identified the interaction of Gag with ABCE1 (also called HP68 or RNase L inhibitor) (Zimmerman et al., 2002), a member of subfamily E of the ATP-binding cassette (ABC) ATPases (Dean et al., 2001). The authors showed that ABCE1 interacts with capsid assembly intermediates and is essential for immature capsid formation in a cell-free system, a notion confirmed by expressing an ABCE1 dominant-negative protein in cells (Zimmerman et al., 2002). Because ABCE1 binding appears to promote conformational changes in nascent capsid structure (Zimmerman et al., 2002), this ATPase may act as a Gag chaperone during oligomerization to facilitate viral particle assembly. Indeed, the function of ABCE1 in the capsid assembly pathway is energy-dependent and occurs in a stepwise manner, involving its progressive association to assembly intermediates (Dooher and Lingappa, 2004). Moreover, the requirement of $\mathrm{ABCE} 1$ is conserved for several primate lentivirus capsids, such as HIV-1, HIV-2, and simian immunodeficiency viruses ( $\mathrm{SIV}_{\text {mac239 }}$ and SIV $_{\text {agm }}$ ) (Dooher and Lingappa, 2004) and non-primate lentiviruses, such as the feline immunodeficiency virus (FIV) (Reed et al., 2018). 
A basic amino acid residue within the nucleocapsid (NC) domain of Gag is important for the recruitment of ABCE1, and Gag molecules carrying mutations in this residue fail to form fully assembled capsids (Lingappa et al., 2006). Indeed, double immunogold labeling followed by cryo-EM revealed that ABCE1 is redirected to the Gag assembly site depending on the integrity of the critical basic residue in NC (Dooher et al., 2007). Interestingly, further research showed that ABCE1 does not bind NC directly. Instead, Gag dimerization promoted by $\mathrm{NC}$ exposes an ABCE1-binding domain located outside the NC (Klein et al., 2011). Moreover, ABCE1 interacts with TULA (Tcell Ubiquitin Ligand) and recruits it to HIV-1 Gag assembly sites, where TULA acts in late steps of the HIV-1 replication cycle (Smirnova et al., 2008).

Evidence for the relevance of ABCE1 in HIV-1-positive patients has been reported. Resequencing analysis of the $A B C E 1$ gene and genomic comparisons revealed an excess of rare genetic variations in the $A B C E 1$ gene among HIV-1-positive AfricanAmerican individuals compared to those among populations of European descent, suggesting positive selection through $A B C E 1$ and the surrounding genomic regions (Crawford et al., 2009; previously reviewed in Tian et al., 2012). Indeed, by using $\mathrm{CD}^{+} \mathrm{T}$ cells from healthy donors and an ex vivo $\mathrm{CD}^{+}{ }^{+} \mathrm{T}$ cell HIV-1 infection system, the authors found that an insertion/deletion variant (rs9333571) in the ABCE1 gene decreased HIV-1 permissiveness (Bleiber et al., 2005; previously reviewed in Tian et al., 2012). These findings are suggestive of ABCE1 importance in HIV-1 infection/pathogenesis. However, additional studies are necessary to correlate the findings in vitro regarding the role of $A B C E 1$ in particle assembly with a possible function of this ATPase in infection in vivo.

\section{The AAA ATPase VPS4}

The ESCRT (Endosomal Sorting Complex Required for Transport) machinery comprises four distinct multimeric complexes (ESCRT-0 to ESCRT-III) that work sequentially to coordinate the formation of the ILVs of late endosomes/MVBs and the selection of ubiquitinated and non-ubiquitinated cargo proteins (daSilva et al., 2009; Dores et al., 2012a,b; Amorim et al., 2014; previously reviewed in Hurley et al., 2020). The selection of the cargo begins in subdomains of early endosomes enriched in clathrin and HRS (hepatocyte growth factor-regulated tyrosine kinase substrate), one of the components of the ESCRT-0 complex (Raiborg et al., 2002). HRS interacts with both the cargo and ESCRT-I, which also binds ESCRT-II. The ESCRT-III complex is subsequently recruited and mediates the invagination of the endosome limiting membrane and the fission of ILVs. VPS4 (vacuolar protein sorting 4), an AAA-ATPase, binds ESCRT-III subunits and catalyzes the disassembly of ESCRTs upon ATP hydrolysis. This latter process facilitates ESCRT machinery recycling and is essential for sustained ILV biogenesis (Lata et al., 2008).

In addition to ILV formation, the ESCRT machinery components function in other cellular processes requiring membrane remodeling, such as in the abscission phase of cytokinesis (Carlton and Martin-Serrano, 2007; Morita et al., 2007; Elia et al., 2011; Guizetti et al., 2011; Peel et al., 2011), and in the regeneration of the nuclear envelope during mitosis (Olmos et al., 2015, 2016; Raab et al., 2016; Ventimiglia et al., 2018; von Appen et al., 2020). HIV and other retroviruses hijack ESCRT machinery components to perform membrane fission events that are topologically equivalent to ILV biogenesis in MVBs, i.e., facing away from the cytosol (Hurley and Hanson, 2010; Peel et al., 2011; Sundquist and Kräusslich, 2012; Freed, 2015). At HIV-1 assembly sites, Gag recruits the ESCRT-I subunit TSG101 (tumor susceptibility gene 101) via the $\mathrm{P}(\mathrm{T} / \mathrm{S}) \mathrm{AP}$ motif present in the Gag p6 domain (Huang et al., 1995; Garrus et al., 2001; Martin-Serrano et al., 2001; VerPlank et al., 2001; Demirov et al., 2002). In an alternative budding pathway, Gag recruits the ESCRT-related protein ALIX (also known AIP1 or PDCD6IP) via an $\mathrm{YPX}_{n} \mathrm{~L}$ motif that is also present in the p6 domain (Strack et al., 2003; Fujii et al., 2009; Usami et al., 2009; Eekels et al., 2011). In addition to ESCRT-I and ALIX, subunits of ESCRT-II were also shown to be important for HIV-1 budding (previously reviewed in Carlson and Hurley, 2012). Notably, the EAP45 protein, a component of the ESCRT-II complex, is required for the late stages of $\mathrm{HIV}-1$ replication via the $\mathrm{YPX}_{n} \mathrm{~L}$-ALIX pathway (Meng et al., 2020).

As a result of Gag interactions with ESCRT-I/ALIX and ESCRT-II, ESCRT-III and, subsequently, VPS4 are also recruited to HIV-1 assembly sites to accomplish membrane scission and viral particle release (Wollert et al., 2009; Bleck et al., 2014; Van Engelenburg et al., 2014). Interestingly, only a subset of the ESCRT-III subunits (the CHMP2 and CHMP4 families) involved in ILV formation are required for HIV-1 budding (Morita et al., 2011).

Polymerization of the CHMP4 and CHMP2 proteins (ESCRTIII subunits) is thought to drive the closure of the membrane neck of a budding virus (Hanson et al., 2008), and lead to exposure of the helical sequence domain in the CHMP2 C-terminus, which in turn binds the MIT domain of the N-terminal region of VPS4. This process allows VPS4 to remove ESCRT-III subunits from the viral membrane neck, culminating in viral membrane fission (Obita et al., 2007; Stuchell-Brereton et al., 2007; Baumgärtel et al., 2011). This VPS4 activity is coupled to ATP hydrolysis, which converts chemical energy into mechanical force to trigger the constriction and cleavage of ESCRT-III polymer ring (Monroe et al., 2017; Schöneberg et al., 2018; Maity et al., 2019). Therefore, the energy required for ESCRT-dependent HIV-1 assembly/budding comes from ATP hydrolysis mediated by VPS4 (previously reviewed in Sundquist and Kräusslich, 2012).

\section{HIV-1 ACCESSORY PROTEINS}

The HIV-1 accessory proteins [Nef, viral protein R (Vpr), viral infectivity factor (Vif), and $\mathrm{Vpu}$ ] are not essential for virus replication in vitro, but they are decisive in creating an intracellular environment that allows efficient viral particle production and spread in vivo (previously reviewed in Sauter and Kirchhoff, 2018). In this section, we discuss how the HIV1 accessory proteins Nef and Vpu co-opt GTPases, ATPases and 
their regulators and effectors to assist in virus replication and to evade host defenses.

\section{Negative Factor (Nef)}

The HIV negative factor (Nef) protein is a critical determinant of viral pathogenesis (Deacon et al., 1995; Gulizia et al., 1997; Oelrichs et al., 1998; Learmont et al., 1999; Gorry et al., 2007). Most of Nef's functions in infection rely on its ability to modify the trafficking of membrane proteins in host cells (previously reviewed in Pereira and daSilva, 2016; Buffalo et al., 2019). Among the targets of Nef is the ATPase $A B C A 1$, an $A B C$ transporter family member that mediates lipid efflux from cells and contributes to the biogenesis of HDL (high-density lipoprotein) by transferring phospholipids and cholesterol to extracellular apoA-I (apolipoproteinA-1) molecules (Santamarina-Fojo et al., 2001; Neufeld et al., 2004; Fitzgerald et al., 2010; Kang et al., 2010).

As previously mentioned, HIV-1 assembly platforms at the cell surface are enriched in PI(4,5)P2 and lipid rafts, which contain high levels of cholesterol and sphingolipids (Nguyen and Hildreth, 2000; Ono and Freed, 2004; Hogue et al., 2011). There is evidence that Nef contributes to the enrichment of cholesterol on lipid rafts at the PM by impeding ABCA1mediated cholesterol efflux (Zheng et al., 2003; Mujawar et al., 2006; Fitzgerald et al., 2010; Cui et al., 2012). There are at least two proposed mechanisms underlying Nef's antagonism to ABCA1 (Figure 3). First, Nef was shown to retain ABCA1 in the $\mathrm{ER}$ and stimulate $\mathrm{ABCA} 1$ proteasome-mediated degradation (Mujawar et al., 2010). Although the binding of Nef to ABCA1 (via its C-terminal domain - $\mathrm{ABCA1}_{2225-2231 a a}$ ) was demonstrated, an ABCA1 mutant that does not interact with Nef also failed to exit the ER and was degraded in response to Nef expression (Mujawar et al., 2010). Rather than acting directly on ABCA1, Nef appears to disrupt the association between newly synthesized ABCA1 and the ER chaperone calnexin, which leads to the enhanced degradation of ABCA1 via the proteasomal/endoplasmic-reticulum-associated protein degradation (ERAD) pathway (Jennelle et al., 2014).

There is also evidence that Nef targets surface ABCA1 for lysosomal degradation (Cui et al., 2012). In support of this alternative model, the authors of one study show that in Nefexpressing cells, $\mathrm{ABCA} 1$ was relocated from the $\mathrm{PM}$ to lysosomes for degradation (Cui et al., 2012). Interestingly, the effects of Nef on ABCA1 during HIV-1 infection may not be restricted to infected cells, as exogenous Nef taken up by cells was also shown to be active in ABCA1 downregulation and cholesterol efflux reduction (Mukhamedova et al., 2019) (Figure 3). Nef antagonism of ABCA1 is likely relevant in HIV-1 pathogenesis, as ABCA1 downregulation and low HDL cholesterol levels were found in HIV-1 treatment-naïve patients, an effect that was reverted by HAART (Feeney et al., 2013; Lo et al., 2014; Thangavel et al., 2018).

Another ATPase that interacts with $\mathrm{Nef}$ is the vacuolar $\mathrm{H}^{+}$ATPase (also known as V-ATPase or $\mathrm{V}_{1} \mathrm{~V}_{0}$-ATPase), a multimeric complex that mediates the acidification of cellular compartments, such as the Golgi complex, endosomes and lysosomes, by pumping protons into their lumen (Oot et al.,
2017). Nef interaction with V-ATPase is thought to occur via its regulatory subunit $\mathrm{H}(\mathrm{V} 1 \mathrm{H})$, also known as Nef binding protein 1 (NBP1), relying on the C-terminal flexible loop of Nef ( $\mathrm{Lu}$ et al., 1998). As the depletion of NBP1, or the disruption of NBP-1-Nef interaction, impaired the Nef-mediated reduction of cell-surface CD4 levels, the authors suggested that Nef interaction with V-ATPase plays a role in CD4 downregulation (Lu et al., 1998). Furthermore, $\mathrm{V}_{1} \mathrm{H}$ binds the $\mu 2$ subunit of the endocytic clathrin adaptor AP-2 (AP-2 $\mu 2)$, via the 133-363aa domain of $\mathrm{V}_{1} \mathrm{H}$ and the N-terminal $\left(1-145_{a a}\right)$ domain of AP- $2 \mu 2$, which led to the proposal of a refined model in which the V-ATPase connects Nef with the endocytic machinery (Geyer et al., 2002). Nef was later shown to bind AP-2 directly (Chaudhuri et al., 2007; Ren et al., 2014) and to bridge AP-2 to CD4 (Januário and daSilva, 2020; Kwon et al., 2020); therefore, the relative importance of $\mathrm{V}_{1} \mathrm{H}$ in this process remains an open question. Moreover, the fact that $\mathrm{V}_{1} \mathrm{H}$ overexpression inhibits the Nef-mediated increase in HIV-1 infectivity (Geyer et al., 2002) indicates that this host factor may be involved in additional Nef actions.

In a different role, Nef changes protein trafficking by usurping the vesicle-sorting machinery regulated by the GTPase ARF1 (Figure 3). This strategy is applied, for instance, to prevent viral antigen presentation by major histocompatibility complex I (MHC-I) molecules, a process that contributes to HIV-1 immune evasion (Cohen et al., 1999; Specht et al., 2008; previously reviewed in Pereira and daSilva, 2016). Nef precludes the delivery of newly synthesized MHC-I molecules to the cell surface, redirecting their transport from the TGN to the endolysosomal system for degradation (previously reviewed in Pereira and daSilva, 2016). As previously mentioned, the clathrin adaptor AP-1 is recruited by ARF- 1 to TGN membranes to form clathrincoated vesicles (CCVs) that are destined for endosomes. In fact, MHC-I downregulation by Nef was shown to require AP1 (Williams et al., 2002; Roeth et al., 2004; Lubben et al., 2007; Schaefer et al., 2008; Leonard et al., 2011; Jia et al., 2012; Tavares et al., 2020) and ARF-1 activity (Wonderlich et al., 2011). Structural analysis revealed that ARF-1-GTP binding to AP1 triggers conformational changes in AP-1, which acquires an 'unlocked' state that is compatible with vesicle-cargo binding (Ren et al., 2013). Intensive research into the mechanism of MHC-I downregulation by Nef revealed that the viral protein links the cytosolic tail of MHC-I to AP-1. Specifically, in the presence of the MHC-I cytosolic tail and ARF-1, Nef induces the trimerization of unlocked AP-1 in an "open" conformation that promotes CCV biogenesis (Shen et al., 2015).

Strikingly, a very similar strategy is used by Nef to prevent the cell surface delivery of the host restriction factor BST2 (also known as Tetherin) through retention at the TGN. In the presence of the cytosolic tail of BST2, Nef changes ARF1-mediated AP-1 trimerization to a "closed" conformation that appears to be incompatible with CCV assembly (Shen et al., 2015). The structural basis for the cargo-dependent diversity of Nef-induced AP-1 trimerization was recently elucidated, and it was also revealed that it is finely tuned by the phosphorylation state of Nef (daSilva and Mardones, 2018; Morris et al., 2018).

The hijacking of ARF-1-mediated trafficking pathways by Nef may also occur beyond the TGN. It has been reported that 


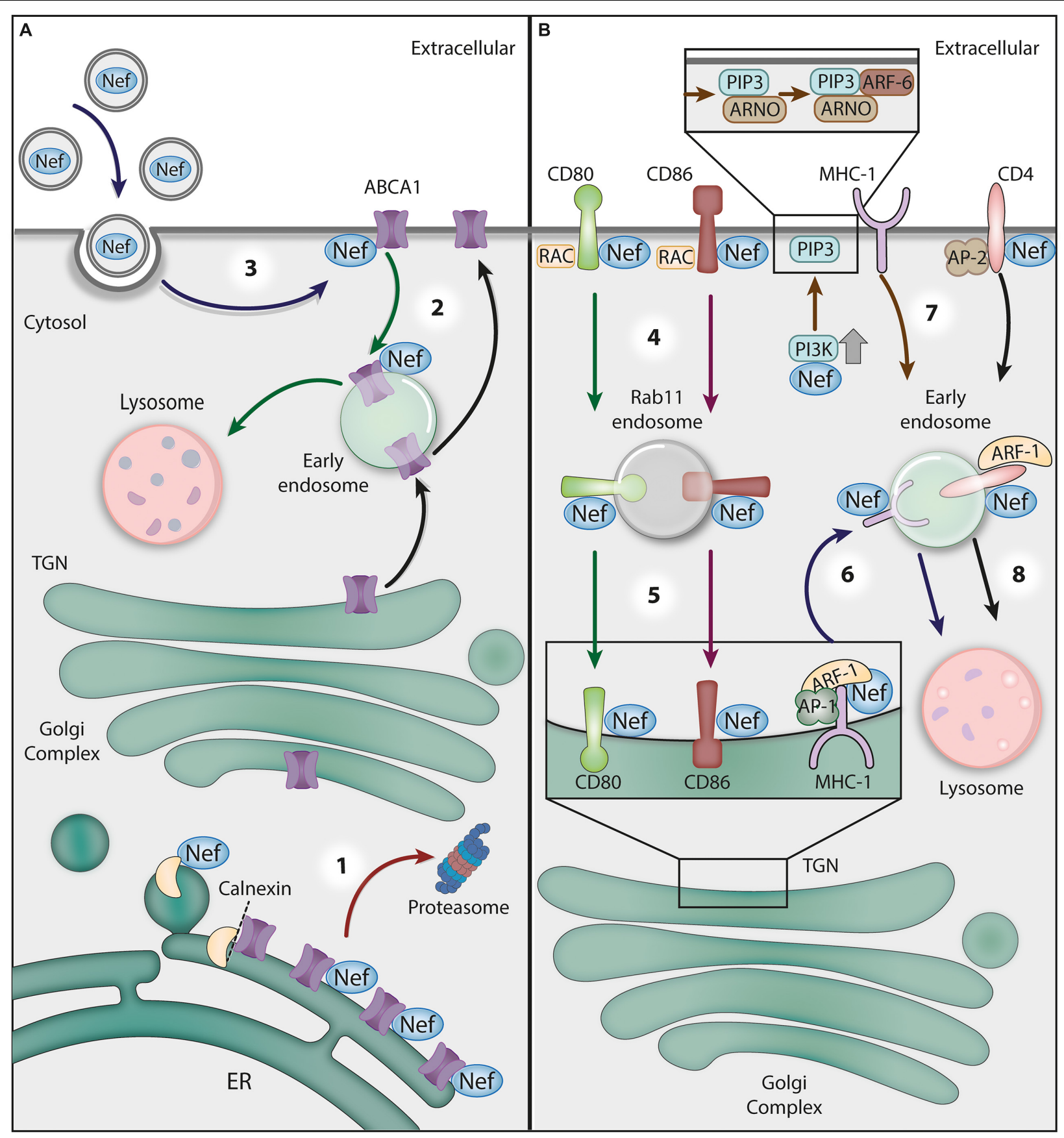

FIGURE 3 | The crosstalk between HIV-1 Nef and GTPases and ATPases in protein trafficking. (A) The Nef-mediated downregulation of ABCA1 ATPase. (1) Nef disrupts the interaction between newly synthesized ABCA1 and the ER chaperone calnexin, leading to the targeting of ABCA1 to the ERAD/proteasomal pathway (red arrow). (2) Additionally, Nef directs ABCA1 molecules that reach the plasma membrane (PM) to lysosomes for degradation (green arrows). (3) Recently, it has been proposed that Nef obtained from extracellular vesicles taken up by bystander cells may also downregulate ABCA1 (blue arrows). (B) Nef hijacks GTPase activities for receptor downregulation. (4) Nef interacts with the cytosolic tails of the surface proteins CD80 and CD86 to target them for Rac1 GTPase-dependent endocytosis. Nef stimulates the translocation of Src kinase to the PM, where it activates a Rac GEF (TIAM), which in turn activates Rac1, resulting in actin polymerization nucleation sites at the cell surface. (5) After endocytosis, Nef recruits Rab11- to CD80/CD86-positive vesicles to target them to the Golgi complex (red and green arrows). (6) To prevent MHC-I delivery to the PM, Nef links the MHC-1 CT to AP-1 and induces the ARF-1 GTPase-dependent trimerization of AP-1 into an 'open' conformation. This promotes the recruitment of MHC-I to forming clathrin-coated vesicles destined for endosomes (dark blue arrows). (7) Alternatively, Nef activates PI3K at the PM, leading to PIP3 accumulation, which favors the recruitment of PIP3-binding ARF-6 GEF (ARNO) and the subsequent ARF-6-dependent endocytosis of MHC-I (brown arrow). (8) Nef also induces the endocytosis of CD4 via AP-2/clathrin vesicles and then targets this receptor to lysosomes for degradation through an ARF-1-dependent mechanism (black arrow). 
ARF-1 activity stabilizes Nef in endosome membranes and may facilitate Nef-mediated targeting of CD4 to this compartment for transport to lysosomes for degradation (Fauré et al., 2004). In fact, the expression of an ARF-1 dominant-negative form inhibited Nef-CD4 complex migration toward the lysosome (Fauré et al., 2004), highlighting the importance of ARF-1 in other receptor downregulation strategies utilized by Nef. Interestingly, it has been shown that Nef uses a variant of AP-1 (AP-1- $\gamma 2)$ to retain CD4 (Tavares et al., 2017) and MHC-I (Tavares et al., 2020) in endosomes for lysosomal delivery.

Nef-induced endocytosis via ARF-6 was also proposed to contribute to MHC-I downregulation. Specifically, Nef was shown to activate class I phosphatidylinositol 3-kinases (PI3K), leading to the accumulation of phosphatidylinositol $(3,4,5)$-triphosphate $[\mathrm{PI}(3,4,5) \mathrm{P} 3]$ at the inner leaflet of the PM. This was proposed to favor PM recruitment of the PI3P-binding protein ARF nucleotide-binding site opener (ARNO), an ARF-6 GEF, which stimulates the ARF-6-dependent endocytosis of MHC-I (Blagoveshchenskaya et al., 2002; Hung et al., 2007). Indeed, the pharmacological inhibition of class I PI3K or the overexpression of inactive ARNO was shown to compromise efficient MHC-I downregulation by Nef (Blagoveshchenskaya et al., 2002; Hung et al., 2007).

In addition to MHC-I, Nef also removes the immune costimulatory molecules CD80 and CD86 from the surface in antigen-presenting cells (Figure 3), such as DCs and macrophages, thus interfering with $\mathrm{T}$ cell priming (Chaudhry et al., 2007, 2008). The mechanism differs from that of MHC-I downregulation and involves the activity of Rac1, a small GTPase within the Rho family mentioned earlier in this review. Nef was shown to promote the translocation of Src kinase to the cell periphery, where Src promotes Rac GEF (TIAM) activation, which in turn activates Rac1 (Chaudhry et al., 2007). At the cell surface, Nef interacts with the CD80 and CD86 cytosolic tails and targets these molecules to actin polymerization nucleation sites at the $\mathrm{PM}$ that support endocytosis, possibly via Nef co-interaction with Rac1 itself, facilitating CD80/CD86 internalization (Chaudhry et al., 2007). Additionally, Nef was proposed to recruit Rab11 to vesicles containing internalized CD80/CD86 to return them to the Golgi complex (Chaudhry et al., 2008) (Figure 3).

\section{Viral Protein U (Vpu)}

The viral protein $\mathrm{U}(\mathrm{Vpu})$ encoded by the HIV-1 genome, is a type I transmembrane protein that contributes to viral immune evasion by antagonizing host proteins that are detrimental to virus replication and dissemination. Vpu acts by modifying the intracellular distribution of its targets, frequently directing them to a degradative pathway. Among the targets of Vpu are CD4, HLA-C, Tim-3, BST2 (Tetherin), CD1d and NTB-A (Strebel, 2014; previously reviewed in Sauter and Kirchhoff, 2018; Prévost et al., 2020). In many cases, the mechanisms underlying the actions of $\mathrm{Vpu}$ depend on the participation of GTPases.

Among the most intensively studied functions of $\mathrm{Vpu}$ is its antagonism to BST2, an interferon-induced host restriction factor that attenuates viral transmission by impairing the release of HIV-1 and other enveloped viruses from infected cells (Neil et al., 2008; Van Damme et al., 2008; Perez-Caballero et al., 2009). $\mathrm{Vpu}$ is thought to remove BST2 from HIV budding sites at the PM mainly by preventing naturally internalized and newly synthesized BST2 molecules from reaching the cell surface, eventually leading to its downregulation (Schmidt et al., 2011). Similar to the downregulation of MHC-I by Nef, Vpu also hijacks the ARF-1/AP-1 sorting machinery to antagonize BST2. Specifically, Vpu was shown to form a tripartite complex with BST2 and AP-1 at the TGN that is thought to load BST2 into CCVs destined for endosomes and to block the resupply of BST2 to the PM (Jia et al., 2012).

$\mathrm{Vpu}$ was also shown to target BST2 to lysosomes for degradation (Mitchell et al., 2009; Dubé et al., 2010). In this regard, the GTPase Rab7A plays a key role in the constitutive turnover of BST2, and its depletion was shown to compromise BST2 endolysosomal degradation induced by Vpu (Caillet et al., 2011). HRS, a component of the ESCRT-0 machinery, has also been shown to participate in Vpu-mediated BST2 downregulation by recognizing ubiquitinated BST2 and targeting it for lysosomal degradation via the MVB pathway (Janvier et al., 2011). Therefore, another energy-harnessing molecule likely involved in the antagonism of BST2 by Vpu is the AAAATPase VPS4, whose activity, as previously discussed, is essential for ESCRT function at MVBs.

\section{FINAL CONSIDERATIONS AND FUTURE DIRECTIONS}

The spatiotemporal control of viral and host proteins distribution in infected cells is key to several steps in the HIV-1 replication cycle. These processes require specialized transport machinery and demand chemical energy, which is supplied by the host cells through ATP and GTP hydrolysis. With the exception of the reverse transcriptase and the integrase, other HIV-1 proteins do not possess known ATP or GTP binding properties and are incapable of directly harnessing energy from these molecules. Instead, HIV-1 factors repurpose host GTPases (such as Dynamin and small GTPases - Ran, Rab, ARF, and Rho family members) and ATPases (such as ABCE1, ABCA1 and VPS4) to regulate: (1) the subcellular distribution of viral components, (2) the subcellular distribution of host proteins that affect virus replication and infectivity and, (3) membrane remodeling reactions required for viral entry and assembly/egress. Several examples of these strategies are discussed here, and many others are likely to arrive.

Despite the outstanding effort in understating the interplay between HIV-1 and energy-related proteins, questions issues remain unsolved. These include, but are not limited to: (1) Why the function of Dynamin in endocytosis, Rab5, and Rab7 is relevant in HIV-1 entry in only some cell types? (2) Which is the precise role of ABCE1 in HIV-1 infection in vivo? (3) What are the mechanisms used by the HIV-1 to activate Rho GTPases and their downstream effectors to modulate the actin 
cytoskeleton? (4) How can ARF-1, Rab8A, and Rab29-mediated transport pathways influence Gag targeting tetraspanin-enriched microdomains during the VSs? (5) Which is the primary model that explains ABCA1 downregulation by Nef? (6) Why is the binding of Nef to the vacuolar $\mathrm{H}+$ ATPase important in CD4 downregulation if Nef can directly bridge CD4 to AP-2?

To address these questions, efforts should be directed to using cellular models that are physiologically relevant for HIV infection and validating the findings using primary human cells and animal models when possible. RNAi and knockout library screening techniques, the several novel high-resolution imaging approaches, and the multiple structural and biochemical methods that became available in recent years will help shed light on these unsolved issues.

Besides contributing to viral fitness, deviating these energyrelated molecules from their normal cell function may have broader cellular physiology effects, which likely influences HIV1 pathogenesis. In this respect, drugs that interfere with specific GTPases or ATPases function may represent potential new anti$\mathrm{HIV}$ agents candidates. Moreover, efforts to discover specific interactions between HIV-1 factors and energy-related molecules may offer new targets for small molecule inhibitors to develop additional anti-HIV therapies.

\section{REFERENCES}

Aepfelbacher, M., Essler, M., Huber, E., Czech, A., and Weber, P. C. (1996). Rho Is a Negative Regulator of Human Monocyte Spreading. J. Immunol. 157, 5070-5. Aggarwal, A., Hitchen, T. L., Ootes, L., McAllery, S., Wong, A., Nguyen, K., et al. (2017). HIV infection is influenced by dynamin at 3 independent points in the viral life cycle. Traffic 18, 392-410. doi: 10.1111/tra.12481

Alford, J. E., Marongiu, M., Watkins, G. L., and Anderson, E. C. (2016). Human Immunodeficiency Virus Type 2 (HIV-2) Gag Is Trafficked in an AP-3 and AP-5 Dependent Manner. PLoS One 11:e0158941. doi: 10.1371/journal.pone. 0158941

Alkhatib, G., Combadiere, C., Broder, C. C., Feng, Y., Kennedy, P. E., Murphy, P. M., et al. (1996). CC CKR5: A RANTES, MIP- $1 \alpha$, MIP-1 $\beta$ receptor as a fusion cofactor for macrophage-tropic HIV-1. Science 272, 1955-8. doi: 10. $1126 /$ science. 272.5270 .1955

Amorim, N. A., da Silva, E. M., de Castro, R. O., da Silva-Januário, M. E., Mendonça, L. M., Bonifacino, J. S., et al. (2014). Interaction of HIV-1 Nef protein with the host protein Alix promotes lysosomal targeting of CD4 receptor. J. Biol. Chem. 289, 27744-27756. doi: 10.1074/jbc.M114.560193

Askjaer, P., Jensen, T. H., Nilsson, J., Englmeier, L., and Kjems, J. (1998). The specificity of the CRM1-Rev nuclear export signal interaction is mediated by RanGTP. J. Biol. Chem. 273, 33414-22. doi: 10.1074/jbc.273.50.33414

Barrero-Villar, M., Barroso-González, J., Cabrero, J. R., Gordón-Alonso, M., Álvarez-Losada, S., Muñoz-Fernández, M. A., et al. (2008). PI4P5-Kinase I $\alpha$ Is Required for Efficient HIV-1 Entry and Infection of T Cells. J. Immunol. 181, 6882-8. doi: 10.4049/jimmunol.181.10.6882

Batonick, M., Favre, M., Boge, M., Spearman, P., Höning, S., and Thali, M. (2005). Interaction of HIV-1 Gag with the clathrin-associated adaptor AP-2. Virology 342, 190-200. doi: 10.1016/j.virol.2005.08.001

Baumgärtel, V., Ivanchenko, S., Dupont, A., Sergeev, M., Wiseman, P. W., Kräusslich, H. G., et al. (2011). Live-cell visualization of dynamics of HIV budding site interactions with an ESCRT component. Nat. Cell Biol. 13, 469474. doi: $10.1038 /$ ncb2215

Bayliss, R., Wheeldon, J., Caucheteux, S. M., Niessen, C. M., and Piguet, V. (2020). Identification of Host Trafficking Genes Required for HIV-1 Virological Synapse Formation in Dendritic Cells. J. Virol. 94, e01597-19. doi: 10.1128/JVI. 01597-19

\section{AUTHOR CONTRIBUTIONS}

All authors listed have made a substantial, direct and intellectual contribution to the work, and approved it for publication.

\section{FUNDING}

Research in the authors' laboratory is supported by the Fundação de Amparo à Pesquisa do Estado de São Paulo (São Paulo Research Foundation; FAPESP) grant (2018/00297-7) and Fundação de Apoio ao Ensino, Pesquisa e Assistência do Hospital das Clínicas da Faculdade de Medicina de Ribeirão Preto da Universidade de São Paulo (FAEPA) grants to LdS. LT and YJ were supported by doctoral scholarships (2016/18207-9 and 2017/12022-0, respectively) from FAPESP. LdS is recipient of a long-standing investigator scholarship from CNPq.

\section{ACKNOWLEDGMENTS}

The authors thank Ana C. A. V. Kayano from Biopic3D for the illustrations.

Behrens, R. T., Aligeti, M., Pocock, G. M., Higgins, C. A., and Sherer, N. M. (2017). Nuclear Export Signal Masking Regulates HIV-1 Rev Trafficking and Viral RNA Nuclear Export. J. Virol. 91, e02107-16. doi: 10.1128/JVI.02107-16

Bennett, A. E., Narayan, K., Shi, D., Hartnell, L. M., Gousset, K., He, H., et al. (2009). Ion-abrasion scanning electron microscopy reveals surface-connected tubular conduits in HIV-infected macrophages. PLoS Pathog 5:e1000591. doi: 10.1371/journal.ppat.1000591

Berlioz-Torrent, C., Shacklett, B. L., Erdtmann, L., Delamarre, L., Bouchaert, I., Sonigo, P., et al. (1999). Interactions of the cytoplasmic domains of human and simian retroviral transmembrane proteins with components of the clathrin adaptor complexes modulate intracellular and cell surface expression of envelope glycoproteins. J. Virol. 73, 1350-1361. doi: 10.1128/jvi.73.2.13501361.1999

Blagoveshchenskaya, A. D., Thomas, L., Feliciangeli, S. F., Hung, C. H., and Thomas, G. (2002). HIV-1 Nef downregulates MHC-I by a PACS-1- and PI3Kregulated ARF6 endocytic pathway. Cell 111, 853-866. doi: 10.1016/s00928674(02)01162-5

Bleck, M., Itano, M. S., Johnson, D. S., Thomas, V. K., North, A. J., Bieniasz, P. D., et al. (2014). Temporal and spatial organization of ESCRT protein recruitment during HIV-1 budding. Proc. Natl. Acad. Sci. U. S. A. 111, 12211-12216. doi: 10.1073/pnas.1321655111

Bleiber, G., May, M., Martinez, R., Meylan, P., Ott, J., Beckmann, J. S., et al. (2005). Use of a Combined Ex Vivo/In Vivo Population Approach for Screening of Human Genes Involved in the Human Immunodeficiency Virus Type 1 Life Cycle for Variants Influencing Disease Progression. J. Virol. 79, 12674-12680. doi: 10.1128/jvi.79.20.12674-12680.2005

Blot, G., Janvier, K., Le Panse, S., Benarous, R., and Berlioz-Torrent, C. (2003) Targeting of the human immunodeficiency virus type 1 envelope to the transGolgi network through binding to TIP47 is required for env incorporation into virions and infectivity. J. Virol. 77, 6931-6945. doi: 10.1128/jvi.77.12.6931-6945. 2003

Boman, A. L., Zhang, C. J., Zhu, X., and Kahn, R. A. (2000). A family of ADPribosylation factor effectors that can alter membrane transport through the trans-Golgi. Mol. Biol. Cell. 11, 1241-55. doi: 10.1091/mbc.11.4.1241

Bosch, V., and Pawlita, M. (1990). Mutational analysis of the human immunodeficiency virus type 1 env gene product proteolytic cleavage site. J. Virol. 64, 2337-2344. doi: 10.1128/jvi.64.5.2337-2344.1990 
Brass, A. L., Dykxhoorn, D. M., Benita, Y., Yan, N., Engelman, A., Xavier, R. J., et al. (2008). Identification of host proteins required for HIV infection through a functional genomic screen. Science 319, 921-926. doi: 10.1126/science.1152725

Brügger, B., Glass, B., Haberkant, P., Leibrecht, I., Wieland, F. T., and Kräusslich, H. G. (2006). The HIV lipidome: a raft with an unusual composition. Proc. Natl. Acad. Sci. U. S. A. 103, 2641-2646. doi: 10.1073/pnas.0511136103

Buffalo, C. Z., Iwamoto, Y., Hurley, J. H., and Ren, X. (2019). How HIV Nef Proteins Hijack Membrane Traffic To Promote Infection. J. Virol. 93, e0132219. doi: 10.1128/jvi.01322-19

Bulankina, A. V., Deggerich, A., Wenzel, D., Mutenda, K., Wittmann, J. G., Rudolph, M. G., et al. (2009). TIP47 functions in the biogenesis of lipid droplets. J. Cell Biol. 185, 641-655. doi: 10.1083/jcb.200812042

Burdick, R. C., Li, C., Munshi, M., Rawson, J. M., Nagashima, K., Hu, W. S., et al. (2020). HIV-1 uncoats in the nucleus near sites of integration. Proc. Natl. Acad. Sci. U S A. 117, 5486-5493. doi: 10.1073/pnas.1920631117

Caillet, M., Janvier, K., Pelchen-Matthews, A., Delcroix-Genête, D., Camus, G., Marsh, M., et al. (2011). Rab7A is required for efficient production of infectious HIV-1. PLoS Pathog 7:e1002347. doi: 10.1371/journal.ppat.1002347

Camus, G., Segura-Morales, C., Molle, D., Lopez-Vergès, S., Begon-Pescia, C., Cazevieille, C., et al. (2007). The clathrin adaptor complex AP-1 binds HIV1 and MLV Gag and facilitates their budding. Mol. Biol. Cell 18, 3193-3203. doi: 10.1091/mbc.e06-12-1147

Carlson, L. A., and Hurley, J. H. (2012). In vitro reconstitution of the ordered assembly of the endosomal sorting complex required for transport at membrane-bound HIV-1 Gag clusters. Proc. Natl. Acad. Sci. U. S. A. 109, 16928-16933. doi: 10.1073/pnas.1211759109

Carlton, J. G., and Martin-Serrano, J. (2007). Parallels between cytokinesis and retroviral budding: a role for the ESCRT machinery. Science 316, 1908-1912. doi: 10.1126/science.1143422

Casanova, J. E., Wang, X., Kumar, R., Bhartur, S. G., Navarre, J., Woodrum, J. E., et al. (1999). Association of Rab25 and Rab1la with the apical recycling system of polarized Madin-Darby canine kidney cells. Mol. Biol. Cell 10, 47-61. doi: $10.1091 / \mathrm{mbc} \cdot 10.1 .47$

Chaudhry, A., Das, S. R., Jameel, S., George, A., Bal, V., Mayor, S., et al. (2007). A two-pronged mechanism for HIV-1 Nef-mediated endocytosis of immune costimulatory molecules CD80 and CD86. Cell Host. Microbe 1, 37-49. doi: 10.1016/j.chom.2007.01.001

Chaudhry, A., Das, S. R., Jameel, S., George, A., Bal, V., Mayor, S., et al. (2008). HIV-1 Nef induces a Rab11-dependent routing of endocytosed immune costimulatory proteins CD80 and CD86 to the Golgi. Traffic 9, 1925-1935. doi: $10.1111 / \mathrm{j} .1600-0854.2008 .00802 . \mathrm{x}$

Chaudhuri, R., Lindwasser, O. W., Smith, W. J., Hurley, J. H., and Bonifacino, J. S. (2007). Downregulation of CD4 by Human Immunodeficiency Virus Type 1 Nef Is Dependent on Clathrin and Involves Direct Interaction of Nef with the AP2 Clathrin Adaptor. J. Virol. 81, 3877-90. doi: 10.1128/jvi.02725-06

Checkley, M. A., Luttge, B. G., Mercredi, P. Y., Kyere, S. K., Donlan, J., Murakami, T., et al. (2013). Reevaluation of the Requirement for TIP47 in Human Immunodeficiency Virus Type 1 Envelope Glycoprotein Incorporation. J. Virol. 87, 3561-70. doi: 10.1128/jvi.03299-12

Christ, F., Thys, W., De Rijck, J., Gijsbers, R., Albanese, A., Arosio, D., et al. (2008). Transportin-SR2 Imports HIV into the Nucleus. Curr. Biol. 18, 1192-202. doi: 10.1016/j.cub.2008.07.079

Cohen, G. B., Gandhi, R. T., Davis, D. M., Mandelboim, O., Chen, B. K., Strominger, J. L., et al. (1999). The selective downregulation of class I major histocompatibility complex proteins by HIV-1 protects HIV-infected cells from NK cells. Immunity 10, 661-671. doi: 10.1016/s1074-7613(00)80065-5

Crawford, D. C., Zheng, N., Speelmon, E. C., Stanaway, I., Rieder, M. J., Nickerson, D. A., et al. (2009). An excess of rare genetic variation in ABCE1 among Yorubans and African-American individuals with HIV-1. Genes Immun. 10, 715-721. doi: 10.1038/gene.2009.57

Cribier, A., Ségéral, E., Delelis, O., Parissi, V., Simon, A., Ruff, M., et al. (2011). Mutations affecting interaction of integrase with TNPO3 do not prevent HIV-1 cDNA nuclear import. Retrovirology 8:104. doi: 10.1186/1742-4690-8-104

Cui, H. L., Grant, A., Mukhamedova, N., Pushkarsky, T., Jennelle, L., Dubrovsky, L., et al. (2012). HIV-1 Nef mobilizes lipid rafts in macrophages through a pathway that competes with ABCA1-dependent cholesterol efflux. J. Lipid Res. 53, 696-708. doi: 10.1194/jlr.M023119
Cullen, B. R. (2003). Nuclear mRNA export: insights from virology. Trends Biochem. Sci. 28, 419-424. doi: 10.1016/S0968-0004(03)00142-7

D'Souza-Schorey, C., and Chavrier, P. (2006). ARF proteins: Roles in membrane traffic and beyond. Nat. Rev. Mol. Cell Biol. 7, 347-358. doi: 10.1038/nrm1910

Daecke, J., Fackler, O. T., Dittmar, M. T., and Kräusslich, H.-G. (2005). Involvement of Clathrin-Mediated Endocytosis in Human Immunodeficiency Virus Type 1 Entry. J. Virol. 79, 1581-94. doi: 10.1128/jvi.79.3.1581-1594.2005

daSilva, L. L. P., and Mardones, G. A. (2018). HIV/SIV-Nef: Pas de trois Choreographies to Evade Immunity. Trends Microbiol. 26, 889-891. doi: 10. 1016/j.tim.2018.09.003

daSilva, L. L., Sougrat, R., Burgos, P. V., Janvier, K., Mattera, R., and Bonifacino, J. S. (2009). Human immunodeficiency virus type 1 Nef protein targets CD4 to the multivesicular body pathway. J. Virol. 83, 6578-6590. doi: 10.1128/JVI. 00548-09

De Iaco, A., and Luban, J. (2011). Inhibition of HIV-1 infection by TNPO3 depletion is determined by capsid and detectable after viral cDNA enters the nucleus. Retrovirology 8:98. doi: 10.1186/1742-4690-8-98

de la Vega, M., Marin, M., Kondo, N., Miyauchi, K., Kim, Y., Epand, R. F., et al. (2011). Inhibition of HIV-1 endocytosis allows lipid mixing at the plasma membrane, but not complete fusion. Retrovirology 8:99. doi: 10.1186/17424690-8-99

Deacon, N. J., Tsykin, A., Solomon, A., Smith, K., Ludford-Menting, M., Hooker, D. J., et al. (1995). Genomic structure of an attenuated quasi species of HIV1 from a blood transfusion donor and recipients. Science 270, 988-991. doi: 10.1126/science.270.5238.988

Dean, M., Hamon, Y., and Chimini, G. (2001). The human ATP-binding cassette (ABC) transporter superfamily. J. Lipid Res. 42, 1007-1017. doi: 10.1016/s00222275(20)31588- 1

Dell'Angelica, E. C., Puertollano, R., Mullins, C., Aguilar, R. C., Vargas, J. D., Hartnell, L. M., et al. (2000). GGAs: A family of ADP ribosylation factor-binding proteins related to adaptors and associated with the Golgi complex. J. Cell Biol. 149, 81-94. doi: 10.1083/jcb.149.1.81

Demeulemeester, J., Blokken, J., Houwer, S., Dirix, L., Klaassen, H., Marchand, A., et al. (2018). Inhibitors of the integrase-transportin-SR2 interaction block HIV nuclear import. Retrovirology 15:5. doi: 10.1186/s12977-018-0389-2

Demirov, D. G., Ono, A., Orenstein, J. M., and Freed, E. O. (2002). Overexpression of the N-terminal domain of TSG101 inhibits HIV-1 budding by blocking late domain function. Proc. Natl. Acad. Sci. U. S. A. 99, 955-960. doi: 10.1073/pnas. 032511899

Dharan, A., Bachmann, N., Talley, S., Zwikelmaier, V., and Campbell, E. M. (2020). Nuclear pore blockade reveals that HIV-1 completes reverse transcription and uncoating in the nucleus. Nat. Microbiol. 5, 1088-1095. doi: 10.1038/s41564020-0735-8

Díaz, E., and Pfeffer, S. R. (1998). TIP47: a cargo selection device for mannose 6phosphate receptor trafficking. Cell 93, 433-443. doi: 10.1016/s0092-8674(00) 81171-x

Dong, X., Biswas, A., Süel, K. E., Jackson, L. K., Martinez, R., Gu, H., et al. (2009). Structural basis for leucine-rich nuclear export signal recognition by CRM1. Nature 458, 1136-1141. doi: 10.1038/nature07975

Dong, X., Li, H., Derdowski, A., Ding, L., Burnett, A., Chen, X., et al. (2005). AP-3 directs the intracellular trafficking of HIV-1 Gag and plays a key role in particle assembly. Cell 120, 663-674. doi: 10.1016/j.cell.2004.12.023

Dooher, J. E., and Lingappa, J. R. (2004). Conservation of a stepwise, energysensitive pathway involving HP68 for assembly of primate lentivirus capsids in cells. J. Virol. 78, 1645-1656. doi: 10.1128/jvi.78.4.1645-1656.2004

Dooher, J. E., Schneider, B. L., Reed, J. C., and Lingappa, J. R. (2007). Host ABCE1 is at plasma membrane HIV assembly sites and its dissociation from Gag is linked to subsequent events of virus production. Traffic 8, 195-211. doi: 10.1111/j.1600-0854.2006.00524.x

Dores, M. R., Chen, B., Lin, H., Soh, U. J., Paing, M. M., Montagne, W. A., et al. (2012a). ALIX binds a YPX(3)L motif of the GPCR PAR1 and mediates ubiquitin-independent ESCRT-III/MVB sorting. J. Cell Biol. 197, 407-419. doi: $10.1083 /$ jcb. 201110031

Dores, M. R., Paing, M. M., Lin, H., Montagne, W. A., Marchese, A., and Trejo, J. (2012b). AP-3 regulates PAR1 ubiquitin-independent MVB/lysosomal sorting via an ALIX-mediated pathway. Mol. Biol. Cell 23, 3612-3623. doi: 10.1091/ mbc.E12-03-0251 
Doughman, R. L., Firestone, A. J., and Anderson, R. A. (2003). Phosphatidylinositol phosphate kinases put PI4,5P(2) in its place. J. Membr. Biol. 194, 77-89. doi: 10.1007/s00232-003-2027-7

Dragic, T., Litwin, V., Allaway, G. P., Martin, S. R., Huang, Y., Nagashima, K. A., et al. (1996). HIV-1 entry into CD4+ cells is mediated by the chemokine receptor CC-CKR-5. Nature 381, 667-673. doi: 10.1038/381667a0

Dubay, J. W., Dubay, S. R., Shin, H. J., and Hunter, E. (1995). Analysis of the cleavage site of the human immunodeficiency virus type 1 glycoprotein: requirement of precursor cleavage for glycoprotein incorporation. J. Virol. 69, 4675-4682. doi: 10.1128/jvi.69.8.4675-4682.1995

Dubé, M., Roy, B. B., Guiot-Guillain, P., Binette, J., Mercier, J., Chiasson, A., et al. (2010). Antagonism of tetherin restriction of HIV-1 release by vpu involves binding and sequestration of the restriction factor in a perinuclear compartment. PLoS Pathog. 6:e1000856. doi: 10.1371/journal.ppat.1000856

Eekels, J. J., Geerts, D., Jeeninga, R. E., and Berkhout, B. (2011). Long-term inhibition of HIV-1 replication with RNA interference against cellular cofactors. Antivir. Res. 89, 43-53. doi: 10.1016/j.antiviral.2010.11.005

Elia, N., Sougrat, R., Spurlin, T. A., Hurley, J. H., and Lippincott-Schwartz, J. (2011). Dynamics of endosomal sorting complex required for transport (ESCRT) machinery during cytokinesis and its role in abscission. Proc. Natl. Acad. Sci. U. S. A. 108, 4846-4851. doi: 10.1073/pnas.110271 4108

Fackler, O. T., and Peterlin, B. M. (2000). Endocytic entry of HIV-1. Curr. Biol. 10, 1005-8. doi: 10.1016/S0960-9822(00)00654-0

Fauré, J., Stalder, R., Borel, C., Sobo, K., Piguet, V., Demaurex, N., et al. (2004). ARF1 regulates Nef-induced CD4 degradation. Curr. Biol. 14, 1056-1064. doi: 10.1016/j.cub.2004.06.021

Favard, C., Chojnacki, J., Merida, P., Yandrapalli, N., Mak, J., Eggeling, C., et al. (2019). HIV-1 Gag specifically restricts PI(4,5)P2 and cholesterol mobility in living cells creating a nanodomain platform for virus assembly. Sci. $A d v$. 5:eaaw8651. doi: 10.1126/sciadv.aaw8651

Feeney, E. R., McAuley, N., O’Halloran, J. A., Rock, C., Low, J., Satchell, C. S., et al. (2013). The expression of cholesterol metabolism genes in monocytes from $\mathrm{HIV}$-infected subjects suggests intracellular cholesterol accumulation. J. Infect. Dis. 207, 628-637. doi: 10.1093/infdis/jis723

Feng, Y., Broder, C. C., Kennedy, P. E., and Berger, E. A. (1996). HIV-1 entry cofactor: Functional cDNA cloning of a seven-transmembrane, G proteincoupled receptor. Science 272, 872-877. doi: 10.1126/science.272.5263.872

Fitzgerald, M. L., Mujawar, Z., and Tamehiro, N. (2010). ABC transporters, atherosclerosis and inflammation. Atherosclerosis 211, 361-370. doi: 10.1016/ j.atherosclerosis.2010.01.011

Fornerod, M., Ohno, M., Yoshida, M., and Mattaj, I. W. (1997). CRM1 is an export receptor for leucine-rich nuclear export signals. Cell 90, 1051-1060. doi: 10.1016/s0092-8674(00)80371-2

Fredericksen, B. L., Wei, B. L., Yao, J., Luo, T., and Garcia, J. V. (2002). Inhibition of Endosomal/Lysosomal Degradation Increases the Infectivity of Human Immunodeficiency Virus. J. Virol. 76, 11440-6. doi: 10.1128/jvi.76.22.1144011446.2002

Freed, E. O. (2015). HIV-1 assembly, release and maturation. Nat. Rev. Microbiol. 13, 484-496. doi: 10.1038/nrmicro3490

Freed, E. O., Myers, D. J., and Risser, R. (1989). Mutational analysis of the cleavage sequence of the human immunodeficiency virus type 1 envelope glycoprotein precursor gp160. J. Virol. 63, 4670-4675. doi: 10.1128/jvi.63.11.4670-4675.1989

Fujii, K., Munshi, U. M., Ablan, S. D., Demirov, D. G., Soheilian, F., Nagashima, K., et al. (2009). Functional role of Alix in HIV-1 replication. Virology 391, 284-292. doi: 10.1016/j.virol.2009.06.016

Galandrini, R., Henning, S. W., and Cantrell, D. A. (1997). Different functions of the GTpase Rho in prothymocytes and late pre-T cells. Immunity 7, 163-174. doi: 10.1016/S1074-7613(00)80519-1

Ganley, I. G., Carroll, K., Bittova, L., and Pfeffer, S. (2004). Rab9 GTPase regulates late endosome size and requires effector interaction for its stability. Mol. Biol. Cell. 15, 5420-30. doi: 10.1091/mbc.E04-08-0747

Garcia, E., Nikolic, D. S., and Piguet, V. (2008). HIV-1 replication in dendritic cells occurs through a tetraspanin-containing compartment enriched in AP-3. Traffic 9, 200-214. doi: 10.1111/j.1600-0854.2007.00678.x

García-Expósito, L., Barroso-González, J., Puigdomènech, I., Machado, J. D., Blanco, J., and Valenzuela-Fernández, A. (2011). HIV-1 requires Arf6-mediated membrane dynamics to efficiently enter and infect T lymphocytes. Mol. Biol. Cell 22, 1148-1166. doi: 10.1091/mbc.E10-08-0722

Garrus, J. E., von Schwedler, U. K., Pornillos, O. W., Morham, S. G., Zavitz, K. H., Wang, H. E., et al. (2001). Tsg101 and the vacuolar protein sorting pathway are essential for HIV-1 budding. Cell 107, 55-65. doi: 10.1016/s0092-8674(01) 00506-2

Gerber, P. P., Cabrini, M., Jancic, C., Paoletti, L., Banchio, C., von Bilderling, C., et al. (2015). Rab27a controls HIV-1 assembly by regulating plasma membrane levels of phosphatidylinositol 4,5-bisphosphate. J. Cell Biol. 209, 435-452. doi: 10.1083/jcb.201409082

Geyer, M., Yu, H., Mandic, R., Linnemann, T., Zheng, Y. H., Fackler, O. T., et al. (2002). Subunit H of the V-ATPase binds to the medium chain of adaptor protein complex 2 and connects Nef to the endocytic machinery. J. Biol. Chem. 277, 28521-28529. doi: 10.1074/jbc.M200522200

Gheysen, D., Jacobs, E., de Foresta, F., Thiriart, C., Francotte, M., Thines, D., et al. (1989). Assembly and release of HIV-1 precursor Pr55gag virus-like particles from recombinant baculovirus-infected insect cells. Cell 59, 103-112. doi: 10.1016/0092-8674(89)90873-8

Ghimire, D., Rai, M., and Gaur, R. (2018). Novel host restriction factors implicated in HIV-1 replication. J. Gen. Virol. 99, 435-446. doi: 10.1099/jgv.0.001026

Gillingham, A. K., and Munro, S. (2007). The small G proteins of the Arf family and their regulators. Annu. Rev. Cell Dev. Biol. 23, 579-611. doi: 10.1146/annurev. cellbio.23.090506.123209

Gorry, P. R., McPhee, D. A., Verity, E., Dyer, W. B., Wesselingh, S. L., Learmont, J., et al. (2007). Pathogenicity and immunogenicity of attenuated, nef-deleted HIV-1 strains in vivo. Retrovirology 4:66. doi: 10.1186/1742-4690-4-66

Guizetti, J., Schermelleh, L., Mäntler, J., Maar, S., Poser, I., Leonhardt, H., et al. (2011). Cortical constriction during abscission involves helices of ESCRT-IIIdependent filaments. Science 331, 1616-1620. doi: 10.1126/science.1201847

Gulizia, R. J., Collman, R. G., Levy, J. A., Trono, D., and Mosier, D. E. (1997). Deletion of nef slows but does not prevent CD4-positive T-cell depletion in human immunodeficiency virus type 1 -infected human-PBL-SCID mice. J. Virol. 71, 4161-4164. doi: 10.1128/jvi.71.5.4161-4164.1997

Guo, H. G., Veronese, F. M., Tschachler, E., Pal, R., Kalyanaraman, V. S., Gallo, R. C., et al. (1990). Characterization of an HIV-1 point mutant blocked in envelope glycoprotein cleavage. Virology 174, 217-224. doi: 10.1016/00426822(90)90070-8

Güttler, T., Madl, T., Neumann, P., Deichsel, D., Corsini, L., Monecke, T., et al. (2010). NES consensus redefined by structures of PKI-type and Rev-type nuclear export signals bound to CRM1. Nat. Struct. Mol. Biol. 17, 1367-1376. doi: $10.1038 / \mathrm{nsmb} .1931$

Hales, C. M., Griner, R., Hobdy-Henderson, K. C., Dorn, M. C., Hardy, D., Kumar, R., et al. (2001). Identification and characterization of a family of Rab11-interacting proteins. J. Biol. Chem. 276, 39067-39075. doi: 10.1074/jbc. M104831200

Hallenberger, S., Bosch, V., Angliker, H., Shaw, E., Klenk, H. D., and Garten, W. (1992). Inhibition of furin-mediated cleavage activation of HIV-1 glycoprotein gp160. Nature 360, 358-361. doi: 10.1038/360358a0

Hanna, J., Carroll, K., and Pfeffer, S. R. (2002). Identification of residues in TIP47 essential for Rab9 binding. Proc. Natl. Acad. Sci. U. S. A. 99, 7450-7454. doi: 10.1073/pnas.112198799

Hanson, P. I., Roth, R., Lin, Y., and Heuser, J. E. (2008). Plasma membrane deformation by circular arrays of ESCRT-III protein filaments. J. Cell Biol. 180, 389-402. doi: 10.1083/jcb.200707031

Harmon, B., and Ratner, L. (2008). Induction of the Gaq Signaling Cascade by the Human Immunodeficiency Virus Envelope Is Required for Virus Entry. J. Virol. 82, 9191-205. doi: 10.1128/jvi.00424-08

Harmon, B., Campbell, N., and Ratner, L. (2010). Role of Abl kinase and the wave2 signaling complex in HIV-1 entry at a post-hemifusion step. PLoS Pathog. 6:e1000956. doi: 10.1371/journal.ppat.1000956

Hart, M. J., Sharma, S., ElMasry, N., Qiu, R. G., McCabe, P., Polakis, P., et al. (1996). Identification of a novel guanine nucleotide exchange factor for the Rho GTPase. J. Biol. Chem. 271, 25452-25458. doi: 10.1074/jbc.271.41.25452

Henderson, B. R., and Percipalle, P. (1997). Interactions between HIV Rev and nuclear import and export factors: The Rev nuclear localisation signal mediates specific binding to human importin- $\beta$. J. Mol. Biol. 274, 693-707. doi: 10.1006/ jmbi.1997.1420 
Hodges, A., Sharrocks, K., Edelmann, M., Baban, D., Moris, A., Schwartz, O., et al. (2007). Activation of the lectin DC-SIGN induces an immature dendritic cell phenotype triggering Rho-GTPase activity required for HIV-1 replication. Nat. Immunol. 8, 569-577. doi: 10.1038/ni1470

Hogue, I. B., Grover, J. R., Soheilian, F., Nagashima, K., and Ono, A. (2011). Gag Induces the Coalescence of Clustered Lipid Rafts and Tetraspanin-Enriched Microdomains at HIV-1 Assembly Sites on the Plasma Membrane. J. Virol. 85, 9749-66. doi: 10.1128/jvi.00743-11

Homma, Y., Hiragi, S., and Fukuda, M. (2021). Rab family of small GTPases: an updated view on their regulation and functions. FEBS J. 288, 36-55. doi: $10.1111 /$ febs. 15453

Huang, M., Orenstein, J. M., Martin, M. A., and Freed, E. O. (1995). p6Gag is required for particle production from full-length human immunodeficiency virus type 1 molecular clones expressing protease. J. Virol. 69, 6810-6818. doi: 10.1128/jvi.69.11.6810-6818.1995

Hung, C. H., Thomas, L., Ruby, C. E., Atkins, K. M., Morris, N. P., Knight, Z. A., et al. (2007). HIV-1 Nef Assembles a Src Family Kinase-ZAP-70/Syk-PI3K Cascade to Downregulate Cell-Surface MHC-I. Cell Host Microbe. 1, 121-133. doi: 10.1016/j.chom.2007.03.004

Hurley, J. H., and Hanson, P. I. (2010). Membrane budding and scission by the ESCRT machinery: it's all in the neck. Nat. Rev. Mol. Cell Biol. 11, 556-566. doi: $10.1038 / \mathrm{nrm} 2937$

Hurley, J., Flower, T., and Pavlin, M. R. (2020). The ESCRT Membrane Scission Machine. FASEB J. 34, 1-1. doi: 10.1096/fasebj.2020.34.s1.00214

Itzen, A., and Goody, R. S. (2011). GTPases involved in vesicular trafficking: structures and mechanisms. Semin. Cell Dev. Biol. 22, 48-56. doi: 10.1016/j. semcdb.2010.10.003

Januário, Y. C., and daSilva, L. L. P. (2020). Hijacking of endocytosis by HIV-1 Nef is becoming crystal clear. Nat. Struct. Mol. Biol. 27, 773-775. doi: 10.1038/ s41594-020-0486-5

Janvier, K., Pelchen-Matthews, A., Renaud, J. B., Caillet, M., Marsh, M., and Berlioz-Torrent, C. (2011). The ESCRT-0 component HRS is required for HIV1 Vpu-mediated BST-2/tetherin down-regulation. PLoS Pathog. 7:e1001265. doi: 10.1371/journal.ppat.1001265

Jennelle, L., Hunegnaw, R., Dubrovsky, L., Pushkarsky, T., Fitzgerald, M. L., Sviridov, D., et al. (2014). HIV-1 protein NEF inhibits activity of ATP-binding cassette transporter A1 by targeting endoplasmic reticulum chaperone calnexin. J. Biol. Chem. 289, 28870-84. doi: 10.1074/jbc.M114.583591

Jia, X., Singh, R., Homann, S., Yang, H., Guatelli, J., and Xiong, Y. (2012). Structural basis of evasion of cellular adaptive immunity by HIV-1 Nef. Nat. Struct. Mol. Biol. 19, 701-706. doi: 10.1038/nsmb.2328

Jiménez-Baranda, S., Gómez-Moutón, C., Rojas, A., Martínez-Prats, L., Mira, E., Ana Lacalle, R., et al. (2007). Filamin-A regulates actin-dependent clustering of HIV receptors. Nat. Cell Biol. 9, 838-46. doi: 10.1038/ncb1610

Johnson, D. S., Bleck, M., and Simon, S. M. (2018). Timing of ESCRT-III protein recruitment and membrane scission during HIV-1 assembly. Elife 7:e36221. doi: 10.7554/eLife.36221

Jones, D. M., Alvarez, L. A., Nolan, R., Ferriz, M., Sainz Urruela, R., MassanaMuñoz, X., et al. (2017). Dynamin-2 Stabilizes the HIV-1 Fusion Pore with a Low Oligomeric State. Cell Rep. 18, 443-453. doi: 10.1016/j.celrep.2016.12.032

Joshi, A., Ablan, S. D., Soheilian, F., Nagashima, K., and Freed, E. O. (2009a). Evidence that productive human immunodeficiency virus type 1 assembly can occur in an intracellular compartment. J. Virol. 83, 5375-5387. doi: 10.1128/JVI. 00109-09

Joshi, A., Garg, H., Nagashima, K., Bonifacino, J. S., and Freed, E. O. (2008). GGA and Arf proteins modulate retrovirus assembly and release. Mol. Cell 30 , 227-238. doi: 10.1016/j.molcel.2008.03.015

Joshi, A., Nagashima, K., and Freed, E. O. (2009b). Defects in cellular sorting and retroviral assembly induced by GGA overexpression. BMC Cell Biol. 10:72. doi: 10.1186/1471-2121-10-72

Jouvenet, N., Zhadina, M., Bieniasz, P. D., and Simon, S. M. (2011). Dynamics of ESCRT protein recruitment during retroviral assembly. Nat. Cell Biol. 13, 394-401. doi: 10.1038/ncb2207

Kahn, R. A. (2009). Toward a model for Arf GTPases as regulators of traffic at the Golgi. FEBS Lett. 583, 3872-3879. doi: 10.1016/j.febslet.2009.10.066

Kahn, R. A., Volpicelli-Daley, L., Bowzard, B., Shrivastava-Ranjan, P., Li, Y., Zhou, C., et al. (2005). Arf family GTPases: roles in membrane traffic and microtubule dynamics. Biochem. Soc. Trans. 33, 1269-1272. doi: 10.1042/BST20051269
Kang, M. H., Singaraja, R., and Hayden, M. R. (2010). Adenosine-triphosphatebinding cassette transporter- 1 trafficking and function. Trends Cardiovasc. Med. 20, 41-49. doi: 10.1016/j.tcm.2010.03.006

Kirschman, J., Qi, M., Ding, L., Hammonds, J., Dienger-Stambaugh, K., Wang, J. J., et al. (2018). HIV-1 Envelope Glycoprotein Trafficking through the Endosomal Recycling Compartment Is Required for Particle Incorporation. J. Virol. 92, e01893-17. doi: 10.1128/JVI.01893-17

Klein, K. C., Reed, J. C., Tanaka, M., Nguyen, V. T., Giri, S., and Lingappa, J. R. (2011). HIV Gag-Leucine Zipper Chimeras Form ABCE1-Containing Intermediates and RNase-Resistant Immature Capsids Similar to Those Formed by Wild-Type HIV-1 Gag. J. Virol. 85, 7419-35. doi: 10.1128/jvi.00288-11

Kloer, D. P., Rojas, R., Ivan, V., Moriyama, K., Van Vlijmen, T., Murthy, N., et al. (2010). Assembly of the biogenesis of lysosome-related organelles complex-3 (BLOC-3) and its interaction with Rab9. J. Biol. Chem. 285, 7794-804. doi: 10.1074/jbc.M109.069088

König, R., Zhou, Y., Elleder, D., Diamond, T. L., Bonamy, G. M. C., Irelan, J. T., et al. (2008). Global Analysis of Host-Pathogen Interactions that Regulate Early-Stage HIV-1 Replication. Cell 135, 49-60. doi: 10.1016/j.cell.2008.07.032

Koyama, M., and Matsuura, Y. (2010). An allosteric mechanism to displace nuclear export cargo from CRM1 and RanGTP by RanBP1. EMBO J. 29, 2002-13. doi: 10.1038/emboj.2010.89

Krishnan, L., Matreyek, K. A., Oztop, I., Lee, K., Tipper, C. H., Li, X., et al. (2010). The Requirement for Cellular Transportin 3 (TNPO3 or TRN-SR2) during Infection Maps to Human Immunodeficiency Virus Type 1 Capsid and Not Integrase. J. Virol. 84, 397-406. doi: 10.1128/jvi.01899-09

Kwon, Y., Kaake, R. M., Echeverria, I., Suarez, M., Karimian Shamsabadi, M., Stoneham, C., et al. (2020). Structural basis of CD4 downregulation by HIV-1 Nef. Nat. Struct. Mol. Biol. 27, 822-828. doi: 10.1038/s41594-020-0463- Z

Lamber, E. P., Siedenburg, A. C., and Barr, F. A. (2019). Rab regulation by GEFs and GAPs during membrane traffic. Curr. Opin. Cell Biol. 59, 34-39. doi: 10. 1016/j.ceb.2019.03.004

Larue, R., Gupta, K., Wuensch, C., Shkriabai, N., Kessl, J. J., Danhart, E., et al. (2012). Interaction of the HIV-1 intasome with transportin 3 protein (TNPO3 or TRN-SR2). J. Biol. Chem. 287, 34044-58. doi: 10.1074/jbc.M112.384669

Lata, S., Schoehn, G., Jain, A., Pires, R., Piehler, J., Gottlinger, H. G., et al. (2008). Helical structures of ESCRT-III are disassembled by VPS4. Science 321, 1354-1357. doi: 10.1126/science. 1161070

Learmont, J. C., Geczy, A. F., Mills, J., Ashton, L. J., Raynes-Greenow, C. H. Garsia, R. J., et al. (1999). Immunologic and virologic status after 14 to 18 years of infection with an attenuated strain of HIV-1. A report from the Sydney Blood Bank Cohort. N. Engl. J. Med. 340, 1715-1722. doi: 10.1056/ NEJM199906033402203

Leonard, J. A., Filzen, T., Carter, C. C., Schaefer, M., and Collins, K. L. (2011). HIV1 Nef disrupts intracellular trafficking of major histocompatibility complex class I, CD4, CD8, and CD28 by distinct pathways that share common elements. J. Virol. 85, 6867-6881. doi: 10.1128/JVI.00229-11

Li, C., Burdick, R. C., Nagashima, K., Hu, W. S., and Pathak, V. K. (2021). HIV-1 cores retain their integrity until minutes before uncoating in the nucleus. Proc. Natl. Acad. Sci. 118. doi: 10.1073/pnas.2019467118

Lingappa, J. R., Dooher, J. E., Newman, M. A., Kiser, P. K., and Klein, K. C. (2006). Basic residues in the nucleocapsid domain of $\mathrm{Gag}$ are required for interaction of HIV-1 gag with ABCE1 (HP68), a cellular protein important for HIV-1 capsid assembly. J. Biol. Chem. 281, 3773-3784. doi: 10.1074/jbc.M507255200

Lingappa, J. R., Hill, R. L., Wong, M. L., and Hegde, R. S. (1997). A multistep, ATPdependent pathway for assembly of human immunodeficiency virus capsids in a cell-free system. J. Cell Biol. 136, 567-581. doi: 10.1083/jcb.136.3.567

Lo, J., Rosenberg, E. S., Fitzgerald, M. L., Bazner, S. B., Ihenachor, E. J., Hawxhurst, V., et al. (2014). High-density lipoprotein-mediated cholesterol efflux capacity is improved by treatment with antiretroviral therapy in acute human immunodeficiency virus infection. Open Forum. Infect. Dis. 1:ofu108. doi: 10.1093/ofid/ofu108

Lombardi, D., Soldati, T., Riederer, M. A., Goda, Y., Zerial, M., and Pfeffer, S. R. (1993). Rab9 functions in transport between late endosomes and the trans Golgi network. EMBO J. 12, 677-682. doi: 10.1002/j.1460-2075.1993.tb05701.x

Lopez-Vergès, S., Camus, G., Blot, G., Beauvoir, R., Benarous, R., and BerliozTorrent, C. (2006). Tail-interacting protein TIP47 is a connector between Gag and Env and is required for Env incorporation into HIV-1 virions. Proc. Natl. Acad. Sci. U. S. A. 103, 14947-14952. doi: 10.1073/pnas.0602941103 
Lu, X., Yu, H., Liu, S. H., Brodsky, F. M., and Peterlin, B. M. (1998). Interactions between HIV1 Nef and vacuolar ATPase facilitate the internalization of CD4. Immunity 8, 647-656. doi: 10.1016/s1074-7613(00)80569-5

Lubben, N. B., Sahlender, D. A., Motley, A. M., Lehner, P. J., Benaroch, P., and Robinson, M. S. (2007). HIV-1 Nef-induced down-regulation of MHC class I requires AP-1 and clathrin but not PACS-1 and is impeded by AP-2. Mol. Biol. Cell 18, 3351-3365. doi: 10.1091/mbc.e07-03-0218

Lucera, M. B., Fleissner, Z., Tabler, C. O., Schlatzer, D. M., Troyer, Z., and Tilton, J. C. (2017). HIV signaling through CD4 and CCR5 activates Rho family GTPases that are required for optimal infection of primary CD4+ T cells. Retrovirology 14:4. doi: 10.1186/s12977-017-0328-7

Maddon, P. J., Dalgleish, A. G., McDougal, J. S., Clapham, P. R., Weiss, R. A., and Axel, R. (1986). The T4 gene encodes the AIDS virus receptor and is expressed in the immune system and the brain. Cell 47, 333-348. doi: 10.1016/00928674(86)90590-8

Maekawa, M., Ishizaki, T., Boku, S., Watanabe, N., Fujita, A., Iwamatsu, A., et al. (1999). Signaling from Rho to the actin cytoskeleton through protein kinases ROCK and LIM-kinase. Science 285, 895-8. doi: 10.1126/science.285.54 29.895

Maity, S., Caillat, C., Miguet, N., Sulbaran, G., Effantin, G., Schoehn, G., et al. (2019). VPS4 triggers constriction and cleavage of ESCRT-III helical filaments. Sci. Adv. 5:eaau7198. doi: 10.1126/sciadv.aau7198

Malim, M. H., Böhnlein, S., Hauber, J., and Cullen, B. R. (1989a). Functional dissection of the HIV-1 Rev trans-activator-Derivation of a trans-dominant repressor of Rev function. Cell 3, 431-437. doi: 10.1016/0092-8674(89)9 0416-9

Malim, M. H., Hauber, J., Le, S. Y., Maizel, J. V., and Cullen, B. R. (1989b). The HIV-1 rev trans-activator acts through a structured target sequence to activate nuclear export of unspliced viral mRNA. Nature 338, 254-257. doi: 10.1038/ 338254a0

Marin, M., Kushnareva, Y., Mason, C. S., Chanda, S. K., and Melikyan, G. B. (2019). HIV-1 Fusion with CD4+ T cells is promoted by proteins involved in endocytosis and intracellular membrane trafficking. Viruses 11:100. doi: 10. 3390/v11020100

Martin-Serrano, J., Zang, T., and Bieniasz, P. D. (2001). HIV-1 and Ebola virus encode small peptide motifs that recruit Tsg101 to sites of particle assembly to facilitate egress. Nat. Med. 7, 1313-1319. doi: 10.1038/nm12011313

Matreyek, K. A., and Engelman, A. (2013). Viral and cellular requirements for the nuclear entry of retroviral preintegration nucleoprotein complexes. Viruses 5 , 2483-2511. doi: 10.3390/v5102483

McCune, J. M., Rabin, L. B., Feinberg, M. B., Lieberman, M., Kosek, J. C., Reyes, G. R., et al. (1988). Endoproteolytic cleavage of gp160 is required for the activation of human immunodeficiency virus. Cell 53, 55-67. doi: 10.1016/ 0092-8674(88)90487-4

Mcdougal, J. S., Kennedy, M. S., Sligh, J. M., Cort, S. P., Mawle, A., and Nicholson, J. K. A. (1986). Binding of HTLV-III/LAV to T4+ T cells by a complex of the $110 \mathrm{~K}$ viral protein and the T4 molecule. Science 231, 382-5. doi: 10.1126/ science. 3001934

Meng, B., Ip, N. C. Y., Abbink, T. E. M., Kenyon, J. C., and Lever, A. M. L. (2020). ESCRT-II functions by linking to ESCRT-I in human immunodeficiency virus-1 budding. Cell Microbiol. 22:e13161. doi: 10.1111/cmi.1 3161

Meyer, B. E., and Malim, M. H. (1994). The HIV-1 Rev trans-activator shuttles between the nucleus and the cytoplasm. Genes Dev. 8, 1538-1547. doi: 10.1101/ gad.8.13.1538

Mitchell, R. S., Katsura, C., Skasko, M. A., Fitzpatrick, K., Lau, D., Ruiz, A., et al. (2009). Vpu antagonizes BST-2-mediated restriction of HIV-1 release via $\beta$ TrCP and endo-lysosomal trafficking. PLoS Pathog 5:e1000450. doi: 10.1371/ journal.ppat.1000450

Miyauchi, K., Kim, Y., Latinovic, O., Morozov, V., and Melikyan, G. B. (2009). HIV Enters Cells via Endocytosis and Dynamin-Dependent Fusion with Endosomes. Cell 137, 433-44. doi: 10.1016/j.cell.2009.02.046

Monecke, T., Güttler, T., Neumann, P., Dickmanns, A., Görlich, D., and Ficner, R. (2009). Crystal structure of the nuclear export receptor CRM1 in complex with Snurportin1 and RanGTP. Science 324, 1087-1091. doi: 10.1126/science. 1173388
Monroe, N., Han, H., Shen, P. S., Sundquist, W. I., and Hill, C. P. (2017). Structural basis of protein translocation by the Vps4-Vtal AAA ATPase. Elife 6:e24487. doi: 10.7554/eLife.24487

Morita, E., Sandrin, V., Chung, H. Y., Morham, S. G., Gygi, S. P., Rodesch, C. K., et al. (2007). Human ESCRT and ALIX proteins interact with proteins of the midbody and function in cytokinesis. EMBO J. 26, 4215-4227. doi: 10.1038/sj. emboj.7601850

Morita, E., Sandrin, V., McCullough, J., Katsuyama, A., Baci Hamilton, I., and Sundquist, W. I. (2011). ESCRT-III protein requirements for HIV-1 budding. Cell Host Microbe. 9, 235-42. doi: 10.1016/j.chom.2011.02.004

Morris, K. L., Buffalo, C. Z., Stürzel, C. M., Heusinger, E., Kirchhoff, F., Ren, X., et al. (2018). HIV-1 Nefs Are Cargo-Sensitive AP-1 Trimerization Switches in Tetherin Downregulation. Cell 174, 659-671.e. doi: 10.1016/j.cell.2 018.07 .004

Mujawar, Z., Rose, H., Morrow, M. P., Pushkarsky, T., Dubrovsky, L., Mukhamedova, N., et al. (2006). Human immunodeficiency virus impairs reverse cholesterol transport from macrophages. PLoS Biol. 4:e365. doi: 10. 1371/journal.pbio.0040365

Mujawar, Z., Tamehiro, N., Grant, A., Sviridov, D., Bukrinsky, M., and Fitzgerald, M. L. (2010). Mutation of the ATP cassette binding transporter A1 (ABCA1) C-terminus disrupts HIV-1 Nef binding but does not block the Nef enhancement of ABCA1 protein degradation. Biochemistry 49, 8338-8349. doi: 10.1021/bi100466q

Mukhamedova, N., Hoang, A., Dragoljevic, D., Dubrovsky, L., Pushkarsky, T., Low, H., et al. (2019). Exosomes containing HIV protein Nef reorganize lipid rafts potentiating inflammatory response in bystander cells. PLoS Pathog. 15:e1007907. doi: 10.1371/journal.ppat.1007907

Murray, J. L., Mavrakis, M., McDonald, N. J., Yilla, M., Sheng, J., Bellini, W. J., et al. (2005). Rab9 GTPase Is Required for Replication of Human Immunodeficiency Virus Type 1, Filoviruses, and Measles Virus. J. Virol. 79, 11742-51. doi: 10. 1128/jvi.79.18.11742-11751.2005

Neil, S. J., Zang, T., and Bieniasz, P. D. (2008). Tetherin inhibits retrovirus release and is antagonized by HIV-1 Vpu. Nature 451, 425-430. doi: 10.1038/ nature 06553

Neufeld, E. B., Stonik, J. A., Demosky, S. J., Knapper, C. L., Combs, C. A., Cooney, A., et al. (2004). The ABCA1 transporter modulates late endocytic trafficking: insights from the correction of the genetic defect in Tangier disease. J. Biol. Chem. 279, 15571-15578. doi: 10.1074/jbc.M314160200

Neville, M., Stutz, F., Lee, L., Davis, L. I., and Rosbash, M. (1997). The importinbeta family member Crm1p bridges the interaction between Rev and the nuclear pore complex during nuclear export. Curr. Biol. 7, 767-775. doi: 10.1016/s09609822(06)00335-6

Nguyen, D. H., and Hildreth, J. E. K. (2000). Evidence for Budding of Human Immunodeficiency Virus Type 1 Selectively from Glycolipid-Enriched Membrane Lipid Rafts. J. Virol. 74, 3264-72. doi: 10.1128/jvi.74.7.3264-3272. 2000

Nikolic, D. S., Lehmann, M., Felts, R., Garcia, E., Blanchet, F. P., Subramaniam, S., et al. (2011). HIV-1 activates Cdc42 and induces membrane extensions in immature dendritic cells to facilitate cell-to-cell virus propagation. Blood 118, 4841-4852. doi: 10.1182/blood-2010-09-305417

Nishida, Y., Arakawa, S., Fujitani, K., Yamaguchi, H., Mizuta, T., Kanaseki, T., et al. (2009). Discovery of Atg5/Atg7-independent alternative macroautophagy. Nature 461, 654-658. doi: 10.1038/nature08455

Nydegger, S., Foti, M., Derdowski, A., Spearman, P., and Thali, M. (2003). HIV1 egress is gated through late endosomal membranes. Traffic 4, 902-910. doi: 10.1046/j.1600-0854.2003.00145.x

Obita, T., Saksena, S., Ghazi-Tabatabai, S., Gill, D. J., Perisic, O., Emr, S. D., et al. (2007). Structural basis for selective recognition of ESCRTIII by the AAA ATPase Vps4. Nature 449, 735-739. doi: 10.1038/nature0 6171

Oelrichs, R., Tsykin, A., Rhodes, D., Solomon, A., Ellett, A., McPhee, D., et al. (1998). Genomic sequence of HIV type 1 from four members of the Sydney Blood Bank Cohort of long-term nonprogressors. AIDS Res. Hum. Retrovir. 14, 811-814. doi: 10.1089/aid.1998.14.811

Ohta, Y., Hartwig, J. H., and Stossel, T. P. (2006). FilGAP, a Rho- and ROCKregulated GAP for Rac binds filamin A to control actin remodelling. Nat. Cell Biol. 8, 803-814. doi: 10.1038/ncb1437 
Olmos, Y., Hodgson, L., Mantell, J., Verkade, P., and Carlton, J. G. (2015). ESCRTIII controls nuclear envelope reformation. Nature 522, 236-239. doi: 10.1038/ nature 14503

Olmos, Y., Perdrix-Rosell, A., and Carlton, J. G. (2016). Membrane Binding by CHMP7 Coordinates ESCRT-III-Dependent Nuclear Envelope Reformation. Curr. Biol. 26, 2635-2641. doi: 10.1016/j.cub.2016.0 7.039

Ono, A., and Freed, E. O. (2004). Cell-type-dependent targeting of human immunodeficiency virus type 1 assembly to the plasma membrane and the multivesicular body. J. Virol. 78, 1552-1563. doi: 10.1128/jvi.78.3.1552-1563. 2004

Ono, A., Orenstein, J. M., and Freed, E. O. (2000). Role of the Gag matrix domain in targeting human immunodeficiency virus type 1 assembly. J. Virol. 74, 2855-2866. doi: 10.1128/jvi.74.6.2855-2866.2000

Oot, R. A., Couoh-Cardel, S., Sharma, S., Stam, N. J., and Wilkens, S. (2017). Breaking up and making up: The secret life of the vacuolar H. Protein Sci. 26, 896-909. doi: 10.1002/pro.3147

Peel, S., Macheboeuf, P., Martinelli, N., and Weissenhorn, W. (2011). Divergent pathways lead to ESCRT-III-catalyzed membrane fission. Trends Biochem. Sci. 36, 199-210. doi: 10.1016/j.tibs.2010.09.004

Pereira, E. A., and daSilva, L. L. (2016). HIV-1 Nef: Taking Control of Protein Trafficking. Traffic 17, 976-996. doi: 10.1111/tra.12412

Perez-Caballero, D., Zang, T., Ebrahimi, A., McNatt, M. W., Gregory, D. A., Johnson, M. C., et al. (2009). Tetherin inhibits HIV-1 release by directly tethering virions to cells. Cell 139, 499-511. doi: 10.1016/j.cell.2009.08.039

Pontow, S. E., Heyden, N., Vander, Wei, S., and Ratner, L. (2004). Actin Cytoskeletal Reorganizations and Coreceptor-Mediated Activation of Rac during Human Immunodeficiency Virus-Induced Cell Fusion. J. Virol. 78, 7138-47. doi: 10. 1128/jvi.78.13.7138-7147.2004

Pontow, S., Harmon, B., Campbell, N., and Ratner, L. (2007). Antiviral activity of a Rac GEF inhibitor characterized with a sensitive HIV/SIV fusion assay. Virology 368, 1-6. doi: 10.1016/j.virol.2007.06.022

Prévost, J., Edgar, C. R., Richard, J., Trothen, S. M., Jacob, R. A., Mumby, M. J., et al. (2020). HIV-1 Vpu Downregulates Tim-3 from the Surface of Infected CD4. J. Virol. 94, e01999-19. doi: 10.1128/JVI.01999-19

Qi, M., Williams, J. A., Chu, H., Chen, X., Wang, J. J., Ding, L., et al. (2013). Rab11FIP1C and Rab14 direct plasma membrane sorting and particle incorporation of the HIV-1 envelope glycoprotein complex. PLoS Pathog 9:e1003278. doi: 10.1371/journal.ppat.1003278

Raab, M., Gentili, M., De Belly, H., Thiam, H. R., Vargas, P., Jimenez, A. J., et al. (2016). ESCRT III repairs nuclear envelope ruptures during cell migration to limit DNA damage and cell death. Science 352, 359-362. doi: 10.1126/science. aad7611

Raiborg, C., Bache, K. G., Gillooly, D. J., Madshus, I. H., Stang, E., and Stenmark, H. (2002). Hrs sorts ubiquitinated proteins into clathrin-coated microdomains of early endosomes. Nat. Cell Biol. 4, 394-398. doi: 10.1038/ ncb791

Rameh, L. E., Tolias, K. F., Duckworth, B. C., and Cantley, L. C. (1997). A new pathway for synthesis of phosphatidylinositol-4,5-bisphosphate. Nature 390, 192-196. doi: 10.1038/36621

Randazzo, P. A., Inoue, H., and Bharti, S. (2007). Arf GAPs as regulators of the actin cytoskeleton. Biol. Cell 99, 583-600. doi: 10.1042/bc20070034

Reed, J. C., Westergreen, N., Barajas, B. C., Ressler, D. T. B., Phuong, D. J., Swain, J. V., et al. (2018). Formation of RNA Granule-Derived Capsid Assembly Intermediates Appears To Be Conserved between Human Immunodeficiency Virus Type 1 and the Nonprimate Lentivirus Feline Immunodeficiency Virus. J. Virol. 92, e01761-17. doi: 10.1128/JVI.01761-17

Ren, X., Farías, G. G., Canagarajah, B. J., Bonifacino, J. S., and Hurley, J. H. (2013). Structural basis for recruitment and activation of the AP-1 clathrin adaptor complex by Arf1. Cell 152, 755-767. doi: 10.1016/j.cell.2012.12.042

Ren, X., Park, S. Y., Bonifacino, J. S., and Hurley, J. H. (2014). How HIV-1 Nef hijacks the AP-2 clathrin adaptor to downregulate CD4. Elife 3:e01754. doi: 10.7554/elife.01754

Riederer, M. A., Soldati, T., Shapiro, A. D., Lin, J., and Pfeffer, S. R. (1994). Lysosome biogenesis requires Rab9 function and receptor recycling from endosomes to the trans-Golgi network. J. Cell Biol. 125, 573-582. doi: 10.1083/ jcb.125.3.573
Roeth, J. F., Williams, M., Kasper, M. R., Filzen, T. M., and Collins, K. L. (2004). HIV-1 Nef disrupts MHC-I trafficking by recruiting AP-1 to the MHC-I cytoplasmic tail. J. Cell Biol. 167, 903-913. doi: 10.1083/jcb.200407031

Saad, J. S., Miller, J., Tai, J., Kim, A., Ghanam, R. H., and Summers, M. F. (2006). Structural basis for targeting HIV-1 Gag proteins to the plasma membrane for virus assembly. Proc. Natl. Acad. Sci. U. S. A. 103, 11364-11369. doi: 10.1073/ pnas.0602818103

Sakalian, M., Wills, J. W., and Vogt, V. M. (1994). Efficiency and selectivity of RNA packaging by Rous sarcoma virus Gag deletion mutants. J. Virol. 68, 5969-5981. doi: 10.1128/jvi.68.9.5969-5981.1994

Santamarina-Fojo, S., Remaley, A. T., Neufeld, E. B., and Brewer, H. B. (2001). Regulation and intracellular trafficking of the ABCA1 transporter. J. Lipid Res. 42, 1339-1345. doi: 10.1016/s0022-2275(20)30266-2

Sauter, D., and Kirchhoff, F. (2018). Multilayered and versatile inhibition of cellular antiviral factors by HIV and SIV accessory proteins. Cytokine Growth Factor Rev. 40, 3-12. doi: 10.1016/j.cytogfr.2018.02.005

Schaefer, M. R., Wonderlich, E. R., Roeth, J. F., Leonard, J. A., and Collins, K. L. (2008). HIV-1 Nef targets MHC-I and CD4 for degradation via a final common beta-COP-dependent pathway in T cells. PLoS Pathog 4:e1000131. doi: 10.1371/journal.ppat.1000131

Schmidt, S., Fritz, J. V., Bitzegeio, J., Fackler, O. T., and Keppler, O. T. (2011). HIV$1 \mathrm{Vpu}$ blocks recycling and biosynthetic transport of the intrinsic immunity factor CD317/tetherin to overcome the virion release restriction. MBio 2, e36-e11. doi: 10.1128/mBio.00036-11

Schöneberg, J., Pavlin, M. R., Yan, S., Righini, M., Lee, I. H., Carlson, L. A., et al. (2018). ATP-dependent force generation and membrane scission by ESCRT-III and Vps4. Science 362, 1423-1428. doi: 10.1126/science.aat1839

Selyutina, A., Persaud, M., Lee, K., KewalRamani, V., and Diaz-Griffero, F. (2020). Nuclear import of the HIV-1 core precedes reverse transcription and uncoating. Cell Rep. 32:108201. doi: 10.1016/j.celrep.2020.108201

Shah, V. B., Shi, J., Hout, D. R., Oztop, I., Krishnan, L., Ahn, J., et al. (2013). The Host Proteins Transportin SR2/TNPO3 and Cyclophilin A Exert Opposing Effects on HIV-1 Uncoating. J. Virol. 87:422. doi: 10.1128/jvi.07177-11

Shapiro, A. D., Riederer, M. A., and Pfeffer, S. R. (1993). Biochemical analysis of rab9, a ras-like GTPase involved in protein transport from late endosomes to the trans Golgi network. J. Biol. Chem. 268, 6925-31. doi: 10.1016/s0021-9258(18) 53128-8

Shen, Q. T., Ren, X., Zhang, R., Lee, I. H., and Hurley, J. H. (2015). HIV-1 Nef Hijacks Clathrin coats by stabilizing AP-1: Arf1 polygons. Science 350:aac5137. doi: $10.1126 /$ science.aac5137

Sherer, N. M., Lehmann, M. J., Jimenez-Soto, L. F., Ingmundson, A., Horner, S. M., Cicchetti, G., et al. (2003). Visualization of retroviral replication in living cells reveals budding into multivesicular bodies. Traffic 4, 785-801. doi: 10.1034/j. 1600-0854.2003.00135.x

Shields, A., Witte, W. N., Rothenberg, E., and Baltimore, D. (1978). High frequency of aberrant expression of Moloney murine leukemia virus in clonal infections. Cell 14, 601-609. doi: 10.1016/0092-8674(78)90245-3

Shkriabai, N., Datta, S. A., Zhao, Z., Hess, S., Rein, A., and Kvaratskhelia, M. (2006). Interactions of HIV-1 Gag with assembly cofactors. Biochemistry 45, 4077-4083. doi: 10.1021/bi052308e

Shrivastava, A., Prasad, A., Kuzontkoski, P. M., Yu, J., and Groopman, J. E. (2015). Slit2N Inhibits Transmission of HIV-1 from Dendritic Cells to T-cells by Modulating Novel Cytoskeletal Elements. Sci. Rep. 5:16833. doi: 10.1038/ srep 16833

Siekevitz, M., Josephs, S. F., Dukovich, M., Peffer, N., Wong-Staal, F., and Greene, W. C. (1987). Activation of the HIV-1 LTR by T cell mitogens and the transactivator protein of HTLV-I. Science 238, 1575-8. doi: 10.1126/science.2825351

Smirnova, E. V., Collingwood, T. S., Bisbal, C., Tsygankova, O. M., Bogush, M., Meinkoth, J. L., et al. (2008). TULA proteins bind to ABCE-1, a host factor of HIV-1 assembly, and inhibit HIV-1 biogenesis in a UBA-dependent fashion. Virology 372, 10-23. doi: 10.1016/j.virol.2007.10.012

Spearman, P. (2018). Viral interactions with host cell Rab GTPases. Small GTPases 9, 192-201. doi: 10.1080/21541248.2017.1346552

Specht, A., DeGottardi, M. Q., Schindler, M., Hahn, B., Evans, D. T., and Kirchhoff, F. (2008). Selective downmodulation of HLA-A and -B by Nef alleles from different groups of primate lentiviruses. Virology 373, 229-237. doi: 10.1016/ j.virol.2007.11.019 
Staeheli, P., and Haller, O. (2018). Human MX2/MxB: a Potent Interferon-Induced Postentry Inhibitor of Herpesviruses and HIV-1. J. Virol. 92, e00709-18. doi: 10.1128/jvi.00709-18

Stamnes, M. A., and Rothman, J. E. (1993). The binding of AP-1 clathrin adaptor particles to Golgi membranes requires ADP-ribosylation factor, a small GTPbinding protein. Cell 73, 999-1005. doi: 10.1016/0092-8674(93)90277-W

Stein, B. S., and Engleman, E. G. (1990). Intracellular processing of the gp160 HIV-1 envelope precursor. Endoproteolytic cleavage occurs in a cis or medial compartment of the Golgi complex. J. Biol. Chem. 265, 2640-2649. doi: 10.1016/ s0021-9258(19)39849-7

Stella, A. O., and Turville, S. (2018). All-round manipulation of the actin cytoskeleton by HIV. Viruses 10:63. doi: 10.3390/v10020063

Strack, B., Calistri, A., Craig, S., Popova, E., and Göttlinger, H. G. (2003). AIP1/ALIX is a binding partner for HIV-1 p6 and EIAV p9 functioning in virus budding. Cell 114, 689-699. doi: 10.1016/s0092-8674(03)00653-6

Strebel, K. (2014). HIV-1 Vpu - an ion channel in search of a job. Biochim. Biophys. Acta 1838, 1074-1081. doi: 10.1016/j.bbamem.2013.06.029

Stuchell-Brereton, M. D., Skalicky, J. J., Kieffer, C., Karren, M. A., Ghaffarian, S., and Sundquist, W. I. (2007). ESCRT-III recognition by VPS4 ATPases. Nature 449, 740-744. doi: 10.1038/nature06172

Suhasini, M., and Reddy, T. R. (2009). Cellular proteins and HIV-1 Rev function. Curr. HIV Res. 7, 91-100. doi: 10.2174/157016209787048474

Sundquist, W. I., and Kräusslich, H. G. (2012). HIV-1 assembly, budding, and maturation. Cold Spring Harb. Perspect. Med. 2:a006924. doi: 10.1101/ cshperspect.a006924

Taltynov, O., Demeulemeester, J., Christ, F., De Houwer, S., Tsirkone, V. G., Gerard, M., et al. (2013). Interaction of transportin-SR2 with ras-related nuclear protein (Ran) GTPase. J. Biol. Chem. 288, 25603-25613. doi: 10.1074/jbc.M113.4 84345

Tavares, L. A., de Carvalho, J. V., Costa, C. S., Silveira, R. M., de Carvalho, A. N., Donadi, E. A., et al. (2020). Two Functional Variants of AP-1 Complexes Composed of either $\gamma 2$ or $\gamma 1$ Subunits Are Independently Required for Major Histocompatibility Complex Class I Downregulation by HIV-1 Nef. J. Virol. 94, e02039-19. doi: 10.1128/JVI.02039-19

Tavares, L. A., da Silva, E. M. L., da Silva-Januário, M. E., Januário, Y. C., de Cavalho, J. V., Czernisz, É. S., et al. (2017). CD4 downregulation by the HIV-1 protein Nef reveals distinct roles for the $\gamma 1$ and $\gamma 2$ subunits of the AP- 1 complex in protein trafficking. J. Cell Sci. 130, 429-443. doi: 10.1242/jcs.192104

Taylor, M. J., Lampe, M., and Merrifield, C. J. (2012). A feedback loop between dynamin and actin recruitment during clathrin-mediated endocytosis. PLoS Biol. 10:e1001302. doi: 10.1371/journal.pbio.1001302

Thangavel, S., Mulet, C. T., Atluri, V. S. R., Agudelo, M., Rosenberg, R., Devieux, J. G., et al. (2018). Oxidative Stress in HIV Infection and Alcohol Use: Role of Redox Signals in Modulation of Lipid Rafts and ATP-Binding Cassette Transporters. Antioxid. Redox. Signal. 28, 324-337. doi: 10.1089/ars.2016. 6830

Thomas, A., Mariani-Floderer, C., López-Huertas, M. R., Gros, N., Hamard-Péron, E., Favard, C., et al. (2015). Involvement of the Rac1-IRSp53-Wave2-Arp2/3 Signaling Pathway in HIV-1 Gag Particle Release in CD4 T Cells. J. Virol. 89, 8162-8181. doi: 10.1128/JVI.00469-15

Tian, Y., Han, X., and Tian, D. L. (2012). The biological regulation of ABCE1. IUBMB Life 64, 795-800. doi: 10.1002/iub.1071

Toccafondi, E., Lener, D., and Negroni, M. (2021). HIV-1 Capsid Core: A Bullet to the Heart of the Target Cell. Front. Microbiol. 12:652486. doi: $10.3389 / \mathrm{fmicb}$. 2021.652486

Traub, L. M., Ostrom, J. A., and Kornfeld, S. (1993). Biochemical dissection of AP1 recruitment onto Golgi membranes. J. Cell Biol. 23, 561-73. doi: 10.1083/jcb. 123.3.561

Tritel, M., and Resh, M. D. (2001). The late stage of human immunodeficiency virus type 1 assembly is an energy-dependent process. J. Virol. 75, 5473-5481. doi: 10.1128/JVI.75.12.5473-5481.2001

Truant, R., and Cullen, B. R. (1999). The Arginine-Rich Domains Present in Human Immunodeficiency Virus Type 1 Tat and Rev Function as Direct Importin $\beta$-Dependent Nuclear Localization Signals. Mol. Cell. Biol. 19, 1210-7. doi: $10.1128 / \mathrm{mcb} \cdot 19.2 .1210$

Tybulewicz, V. L., and Henderson, R. B. (2009). Rho family GTPases and their regulators in lymphocytes. Nat. Rev. Immunol. 9, 630-644. doi: 10.1038/nri2606
Ullrich, O., Reinsch, S., Urbé, S., Zerial, M., and Parton, R. G. (1996). Rab11 regulates recycling through the pericentriolar recycling endosome. J. Cell Biol. 135, 913-924. doi: 10.1083/jcb.135.4.913

Usami, Y., Popov, S., Popova, E., Inoue, M., Weissenhorn, W., and Göttlinger, H. (2009). The ESCRT pathway and HIV-1 budding. Biochem. Soc. Trans. 37, 181-184. doi: 10.1042/BST0370181

Vadlamudi, R. K., Li, F., Adam, L., Nguyen, D., Ohta, Y., Stossel, T. P., et al. (2002). Filamin is essential in actin cytoskeletal assembly mediated by $\mathrm{p} 21$-activated kinase 1. Nat. Cell Biol. 4, 681-90. doi: 10.1038/ncb838

Valle-Casuso, J. C., Di Nunzio, F., Yang, Y., Reszka, N., Lienlaf, M., Arhel, N., et al. (2012). TNPO3 Is Required for HIV-1 Replication after Nuclear Import but prior to Integration and Binds the HIV-1 Core. J. Virol. 86, 5931-6. doi: 10.1128/jvi.00451-12

Van Damme, N., Goff, D., Katsura, C., Jorgenson, R. L., Mitchell, R., Johnson, M. C., et al. (2008). The interferon-induced protein BST-2 restricts HIV-1 release and is downregulated from the cell surface by the viral Vpu protein. Cell Host Microbe 3, 245-252. doi: 10.1016/j.chom.2008.03.001

Van Engelenburg, S. B., Shtengel, G., Sengupta, P., Waki, K., Jarnik, M., Ablan, S. D., et al. (2014). Distribution of ESCRT machinery at HIV assembly sites reveals virus scaffolding of ESCRT subunits. Science 343, 653-656. doi: 10.1126/ science. 1247786

Ventimiglia, L. N., Cuesta-Geijo, M. A., Martinelli, N., Caballe, A., Macheboeuf, P., Miguet, N., et al. (2018). CC2D1B Coordinates ESCRT-III Activity during the Mitotic Reformation of the Nuclear Envelope. Dev. Cell. 47, 547-563.e6. doi: 10.1016/j.devcel.2018.11.012

VerPlank, L., Bouamr, F., LaGrassa, T. J., Agresta, B., Kikonyogo, A., Leis, J., et al. (2001). Tsg101, a homologue of ubiquitin-conjugating (E2) enzymes, binds the L domain in HIV type 1 Pr55(Gag). Proc. Natl. Acad. Sci. U. S. A. 98, 7724-7729. doi: $10.1073 /$ pnas. 131059198

Vidricaire, G., and Tremblay, M. J. (2005). Rab5 and Rab7, but not ARF6, govern the early events of HIV-1 infection in polarized human placental cells. J. Immunol. 175, 6517-6530. doi: 10.4049/jimmunol.175.10.6517

von Appen, A., LaJoie, D., Johnson, I. E., Trnka, M. J., Pick, S. M., Burlingame, A. L., et al. (2020). LEM2 phase separation promotes ESCRT-mediated nuclear envelope reformation. Nature 582, 115-118. doi: 10.1038/s41586-020-2232-x

Vorster, P. J., Guo, J., Yoder, A., Wang, W., Zheng, Y., Xu, X., et al. (2011). LIM kinase 1 modulates cortical actin and CXCR4 cycling and is activated by HIV-1 to initiate viral infection. J. Biol. Chem. 286, 12554-64. doi: 10.1074/jbc.M110. 182238

Wang, L., Zhang, H., Solski, P. A., Hart, M. J., Der, C. J., and Su, L. (2000). Modulation of HIV-1 replication by a novel RhoA effector activity. J. Immunol. 164, 5369-5374. doi: 10.4049/jimmunol.164.10.5369

Wang, X., Kumar, R., Navarre, J., Casanova, J. E., and Goldenring, J. R. (2000). Regulation of vesicle trafficking in madin-darby canine kidney cells by Rab1la and Rab25. J. Biol. Chem. 275, 29138-29146. doi: 10.1074/jbc.M004410200

Wilen, C. B., Tilton, J. C., and Doms, R. W. (2012). HIV: Cell binding and entry. Cold Spring Harb. Perspect. Med. 2:a006866. doi: 10.1101/cshperspect.a006866

Williams, M., Roeth, J. F., Kasper, M. R., Fleis, R. I., Przybycin, C. G., and Collins, K. L. (2002). Direct binding of human immunodeficiency virus type $1 \mathrm{Nef}$ to the major histocompatibility complex class I (MHC-I) cytoplasmic tail disrupts MHC-I trafficking. J. Virol. 76, 12173-12184. doi: 10.1128/jvi.76.23.1217312184.2002

Wolins, N. E., Rubin, B., and Brasaemle, D. L. (2001). TIP47 Associates with Lipid Droplets. J. Biol. Chem. 276, 5101-8. doi: 10.1074/jbc.M006775200

Wollert, T., Wunder, C., Lippincott-Schwartz, J., and Hurley, J. H. (2009). Membrane scission by the ESCRT-III complex. Nature 458, 172-177. doi: 10. 1038/nature 07836

Wonderlich, E. R., Leonard, J. A., Kulpa, D. A., Leopold, K. E., Norman, J. M., and Collins, K. L. (2011). ADP ribosylation factor 1 activity is required to recruit AP-1 to the major histocompatibility complex class I (MHC-I) cytoplasmic tail and disrupt MHC-I trafficking in HIV-1-infected primary T cells. J. Virol. 85, 12216-12226. doi: 10.1128/JVI.00056-11

Wyss, S., Berlioz-Torrent, C., Boge, M., Blot, G., Höning, S., Benarous, R., et al. (2001). The highly conserved C-terminal dileucine motif in the cytosolic domain of the human immunodeficiency virus type 1 envelope glycoprotein is critical for its association with the AP-1 clathrin adaptor [correction of adapter]. J. Virol. 75, 2982-2992. doi: 10.1128/JVI.75.6.2982-2992.2001 
Zhang, H., Wang, L., Kao, S., Whitehead, I. P., Hart, M. J., Liu, B., et al. (1999). Functional interaction between the cytoplasmic leucine-zipper domain of HIV1 gp41 and p115-RhoGEF. Curr. Biol. 9, 1271-1274. doi: 10.1016/s09609822(99)80511-9

Zheng, Y. H., Plemenitas, A., Fielding, C. J., and Peterlin, B. M. (2003). Nef increases the synthesis of and transports cholesterol to lipid rafts and HIV-1 progeny virions. Proc. Natl. Acad. Sci. U. S. A. 100, 8460-8465. doi: 10.1073/ pnas. 1437453100

Zhou, L., Sokolskaja, E., Jolly, C., James, W., Cowley, S. A., and Fassati, A. (2011). Transportin 3 promotes a nuclear maturation step required for efficient HIV-1 integration. PLoS Pathog. 7:e1002194. doi: 10.1371/journal.ppat.1002194

Zila, V., Margiotta, E., Turoòová, B., Müller, T. G., Zimmerli, C. E., Mattei, S., et al. (2021). Cone-shaped HIV-1 capsids are transported through intact nuclear pores. Cell 184, 1032-1046.e18. doi: 10.1016/j.cell.2021. 01.025
Zimmerman, C., Klein, K. C., Kiser, P. K., Singh, A. R., Firestein, B. L., Riba, S. C., et al. (2002). Identification of a host protein essential for assembly of immature HIV-1 capsids. Nature 415, 88-92. doi: 10.1038/415 $088 \mathrm{a}$

Conflict of Interest: The authors declare that the research was conducted in the absence of any commercial or financial relationships that could be construed as a potential conflict of interest.

Copyright (c) 2021 Tavares, Januário and daSilva. This is an open-access article distributed under the terms of the Creative Commons Attribution License (CC BY).

The use, distribution or reproduction in other forums is permitted, provided the original author(s) and the copyright owner(s) are credited and that the original publication in this journal is cited, in accordance with accepted academic practice. No use, distribution or reproduction is permitted which does not comply with these terms. 